\section{UCDNN}

LIBRARY
University of Connecticut OpenCommons@UConn

8-13-2014

\title{
Self-Distancing to Reduce Anger in High School Students
}

Koichi Yoshikawa

University of Connecticut - Storrs, suasprinter@hotmail.com

Follow this and additional works at: https://opencommons.uconn.edu/dissertations

\section{Recommended Citation}

Yoshikawa, Koichi, "Self-Distancing to Reduce Anger in High School Students" (2014). Doctoral Dissertations. 499.

https://opencommons.uconn.edu/dissertations/499 


\title{
Self-Distancing to Reduce Anger in High School Students
}

\author{
Koichi Yoshikawa, Ph.D.
}

University of Connecticut, 2014

The present study employed an experimental design to examine the efficacy of self-distancing as an intervention in a sample of high school students for promoting reflective adaptation to anger inducing events relative to a control group using self-reflection/self-immersion. Despite the prevalent assumption that self-reflection facilitates the resolution of negative emotions, evidence demonstrates that self-reflection often leads to anger rumination. Recent experimental studies on college students, elementary school students, and couples have found that self-distancing interventions, as compared to self-immersion/reflection interventions or a no-treatment control, lead to adaptive responses to anger and reductions in future aggression. As adolescents are particularly prone to intense experiences of anger and are at high-risk of being the perpetrators and victims of aggression, examining the potential of self-distancing to reduce anger has important implications for adults serving this population. However, contrary to the results of the literature examining self-distancing in adult and child populations, self-distancing was not found to reduce, and may have increased, implicit aggressive cognition, anger, and negative affect in the adolescent sample. Implications for future research are discussed. 
Self-Distancing to Reduce Anger in High School Students

\author{
Koichi Yoshikawa
}

B.A., Soka University of America, 2005

M.A., Soka University of America, 2006

M.A. University of Connecticut, 2011

Sixth Year, University of Connecticut, 2014

\author{
A Dissertation \\ Submitted in Partial Fulfillment of the \\ Requirements for the Degree of \\ Doctor of Philosophy \\ at the \\ University of Connecticut
}

2014 


\section{Copyright by}

Koichi Yoshikawa

2014 


\title{
APPROVAL PAGE
}

\section{Doctor of Philosophy Dissertation}

\section{Self-Distancing to Reduce Anger in High School Students}

\author{
Presented by
}

Koichi Yoshikawa, B.A., M.A., M.A., Sixth Year

Major Advisor

Thomas Kehle

Associate Advisor

Melissa Bray

Associate Advisor

Hariharan Swaminathan

University of Connecticut

2014 


\section{Acknowledgements}

I wish to dedicate this dissertation to my former students and clients. There tenacity in the face of despair and seemingly insurmountable obstacles inspired me to also move forward and push my limits. Thank you for being in my life.

It is with heartfelt appreciation and deepest gratitude that I recognize the sincere dedication and earnest support of my advisors and readers, Dr. Thomas J. Kehle, Dr. Melissa Bray, Dr. Hariharan Swaminathan, Dr. Del Siegel, and Dr. Chris Rhoads. I am certain that their patience these past four years as they guided me along this path of academia cannot be matched. They are not only kind hearted individuals, but also models of scholarship. And it is with great pride that I regard them as my mentors.

I would also like to thank my family and friends for believing in my potential and for the love that has empowered me to strive to become an individual that can someday repay this great debt of gratitude for the beautiful life given to me. Lastly, I would like to thank my mentor in life, Daisaku Ikeda, who believed in a lost young man and awakened him to a mission. 


\section{TABLE OF CONTENTS}

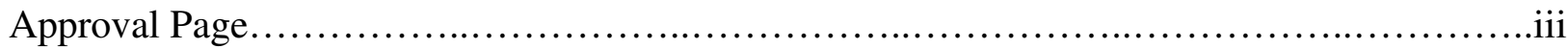

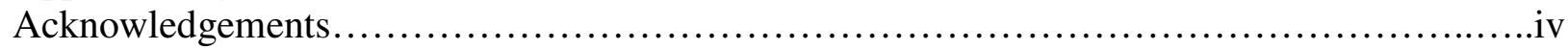

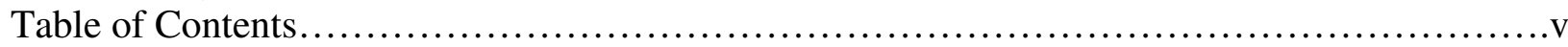

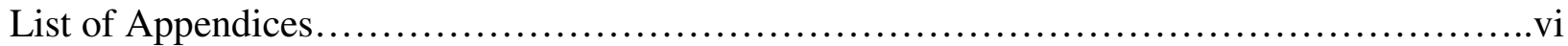

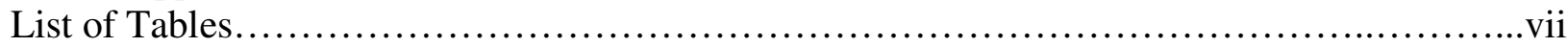

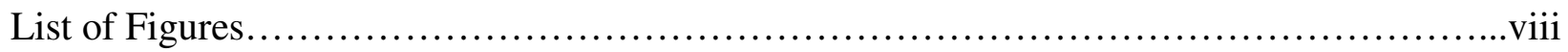

\section{CHAPTER I: INTRODUCTION}

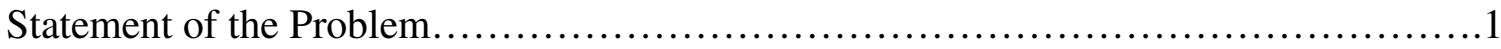

Anger in Adolescents..............................................................

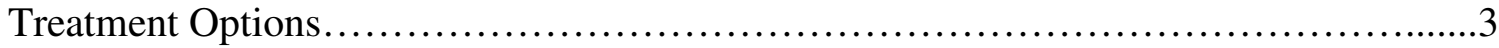

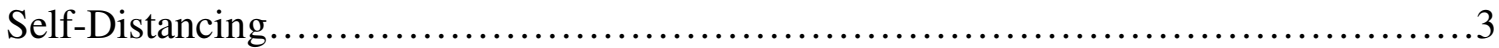

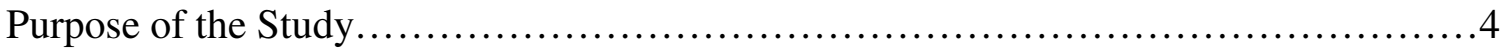

\section{CHAPTER II: REVIEW OF THE LITERATURE}

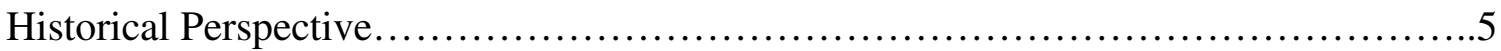

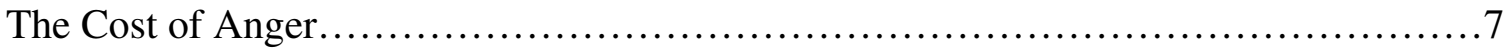

Anger in Children and Adolescents................................................. 10

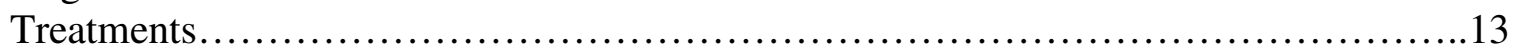

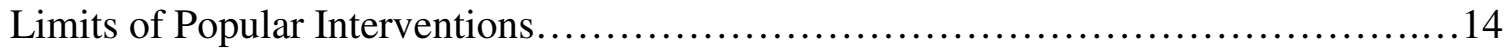

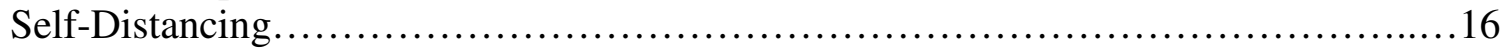

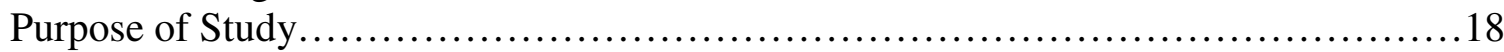

\section{CHAPTER III: METHOD}

Participants Recruitment, and Setting .........................................20

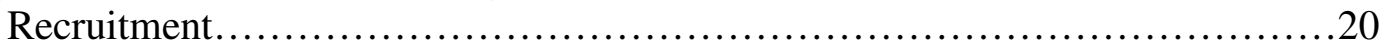

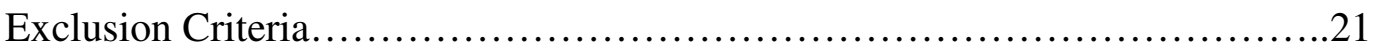

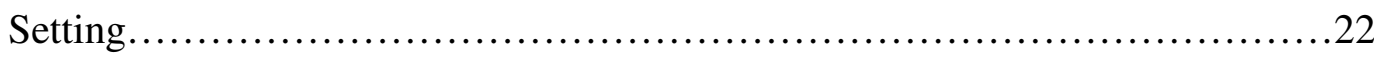

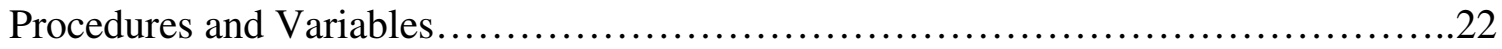

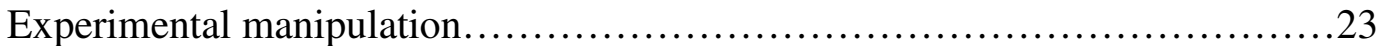

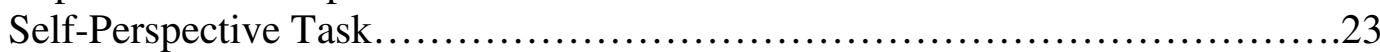

Implicit Aggressive Cognition...............................................24

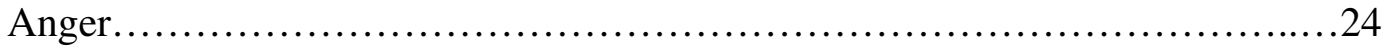

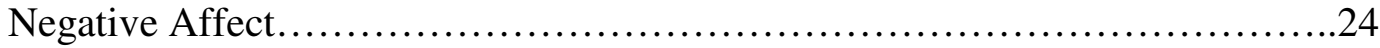

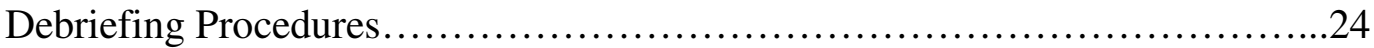

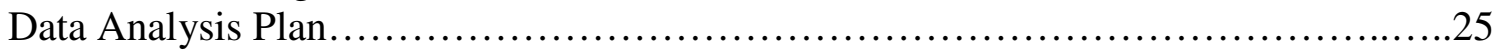

\section{CHAPTER IV: RESULTS}

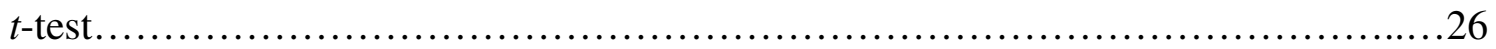




\section{CHAPTER V: DISCUSSION}

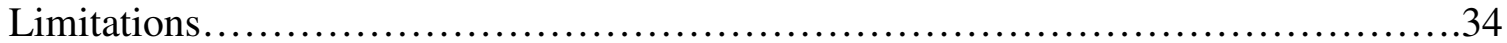

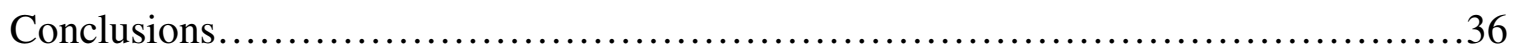

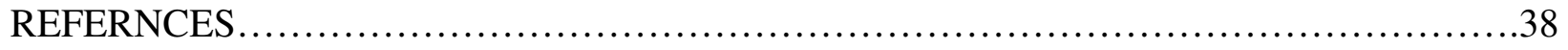

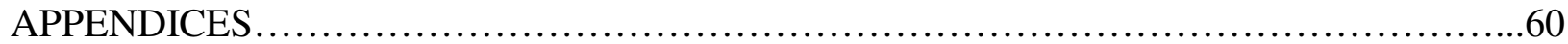

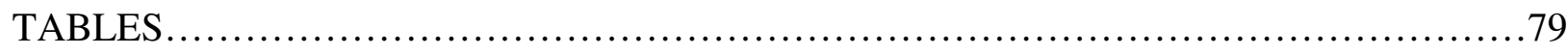

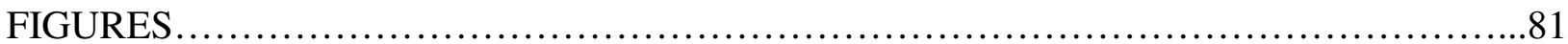




\section{LIST OF APPENDICES}

Appendix A Site Permission Letter..............................................60

Appendix B Recruitment Flyer................................................63

Appendix -C Parental Recruitment/Parent Information Phone Call Script...................64

Appendix -D Parental Permission Form for Participation in a Research Study...............66

Appendix -E Assent Form for Participation in a Research Study $\ldots \ldots \ldots \ldots \ldots \ldots \ldots \ldots \ldots \ldots . \ldots . \ldots \ldots$

Appendix -F Word Completion Task for Implicit Aggressive Cognition....................72

Appendix -G PANAS Scale for Anger and Negative Affect.............................74

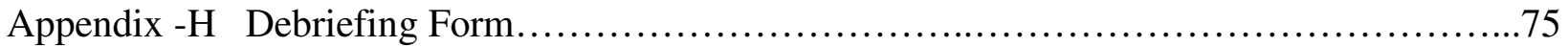

Appendix -J Integrity Checklist............................................... 77 


\section{LIST OF TABLES}

Table 1 Adolescent Scores on Dependent Variables in Control and Self-Distancing Group...79

Table 2 Contrast of Control with Self-Distancing Groups............................. 80 


\section{LIST OF FIGURES}

Figure $1 \quad$ Mean score for implicit aggressive cognition...............................82

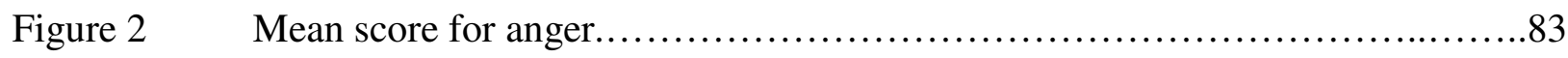

Figure $3 \quad$ Mean score for negative affect........................................ 84

Figure $4 \quad$ Mean score for negative affect minus anger.............................. 85 


\title{
CHAPTER 1
}

\section{INTRODUCTION}

\author{
Statement of the Problem
}

\section{Anger in Adolescents}

The emotion of anger, despite its universality, appears to be a more intense, salient, detrimental, and therefore, dominant experience for adolescents, relative to children and adults, due to the unique physical, psychological, and social changes specific to this developmental period (Blanchard-Fields \& Coates, 2008; Spielberger, 1996; Spielberger, Jacobs, Russell, \& Crane, 1983; Wilde, 1996). Research on adolescents and college undergraduates has noted a link between anger and symptoms such as weight loss, increased systolic and diastolic blood pressure, anorexia, sleep disturbance, withdrawal, confusion, and somatic symptoms such as aches, pains, and gastrointestinal upsets (Freeberg, 1982; Hauber, Rice, Howell, \& Carmon, 1998; Larson \& Kasimatis, 1991). Although past researchers have theorized that anger serves an invigorating function, by increasing the inclination to change, Mahon, Yarcheski, and Yarcheski (2000) have found that for adolescents anger is enervating and drains vigor. Adolescent anger is also disruptive to the functioning of social systems as evidenced by the mental health and correctional facilities rife with cases of angry adolescents that disrupt families, classrooms, the community, and clinical settings with their hostility, resentment, rebelliousness, cynicism, distrust, paranoia, and preoccupation with power and control in relationship dynamics (Cramerus, 1990). When anger is presented with aggression, other long-term consequences include difficulties with peer relationships, school dropout, increased risk for future antisocial behaviors, and substance abuse (Kupersmidt \& Coie, 1990; Moss \& Kirisci, 1995; Pope \& Bierman, 1999). 
Perhaps the most unsettling aspect of adolescent anger is its association with violence and aggression. Anger and aggression not only result in negative emotional, physical, behavioral, educational, systemic, and therapeutic outcomes, but also serious harm, including increased risk for suicide and even homicide (Stein et al., 1998). The National Comorbidity Survey Replication Adolescent Supplement found that $63.2 \%$ of adolescents reported lifetime anger attacks which involved 1) the destruction of property (31.6\%), 2) threatening violence (57.9\%), 3) or engaging in violence (39.3\%), with $72.5 \%$ of these respondents reporting involvement in anger attacks involving more than one of these three behaviors (Green, 2012). These numbers appear consistent with Center for Disease Control and Prevention (CDC; 2010) figures that indicate that violence is also a major cause of nonfatal injuries for youth between the ages of 1024, with 700,000 being treated in emergency rooms in 2011 for nonfatal injuries sustained during assaults. Moreover, males are more likely to engage in dangerous physical aggression, use weapons, and commit homicide (Cornell \& Loper, 1998; Deffenbacher, Oetting, Lynch, \& Morris, 1996; Singer \& Flannery, 2000). Tragically, despite the rate of youth homicide having steadily declined since the mid-1990s, homicide remains a leading cause of death for this population. At the time of this writing, there have been at least 32 incidents of gun violence in schools committed by adolescents 12 to 20 years of age since the tragic Newtown shootings of December 14, 2012. Part of the reason for the association between anger and violence is that anger, unlike other negative emotions, produces a tendency to approach stimuli that may elicit hostility, negative attitudes of resentment and suspicion, which in turn increase the likelihood of an angry response, including indirect and direct verbal or physical aggression (DiGiuseppe \& Tafrate, 2007; Scherer \& Walbott, 1994). Gabel and Shindledecker (1991) have noted that adolescents who exhibit aggressive behavior tend to have a poor therapeutic prognosis. 


\section{Treatment Options}

In contrast to the high global physical, mental, and social costs of unmanaged anger, the ability to control anger has been positively correlated with health and well-being (Yarcheski, Mahon, \&Yarcheski, 2002). One common treatment option for anger is cognitive behavior therapy (CBT). A meta-analysis of clinical studies using CBT on adults and adolescents found a mean weighted effect size of .70 in the reduction of anger (Beck \& Fernandez, 1998). Likewise, Cole's (2008) narrative review of 14 studies of CBT interventions for adolescents with anger difficulties also concluded that these interventions were effective in reducing anger in the shortterm.

\section{Self-Distancing}

Due to the extensively resource and time intensive nature of CBT interventions, researchers have been exploring more efficient preventative interventions such as antecedentfocused strategies which defuse anger prior to full-scale activation of an anger response. Of the antecedent-focused strategies, the most researched are cognitive reappraisals, in which emotional episodes are interpreted or cognitively transformed in an objective, non-emotional manner. Cognitive reappraisals have been found to be an effective and flexible tool to down-regulate even intense negative emotions (Gross, 2001; Ochsner et al., 2004), with individuals who frequently use reappraisals reporting greater positive emotions, less negative emotions (i.e., guilt, sadness, and anxiety), greater cardiac output, greater ventricular contractility, less peripheral resistance, enhanced interpersonal functioning and well-being (Gross \& John, 2003; Mauss, Cook, Cheng, \& Gross, 2007). In particular, individuals who use high level cognitive construals, the application of abstract mental models consisting of general and decontextualized features of an event, are likely to report greater ability to delay gratification, greater physical endurance, greater self-control, and less temptations to undermine self-control, than people who use low level 
construals, which focuses on concrete, contextual, and incidental details (Fujita, Trope, Liberman, \& Levin-Sagi, 2006; Liberman, Sagristano, \& Trope, 2002). The level of a cognitive construal is determined by the psychological distance of an object or event, with distancing a target on psychological dimensions of time, space, social distance or hypotheticality leading to greater high-level construal (Liberman et al., 2002). Psychological distance, thus, plays a major role in determining adaptive from maladaptive forms of reappraisal (Kross, 2009). Thus, when individuals recall negative autobiographical experiences from a self-distanced perspective, in which they see themselves in their experience from the perspective of an observer or "fly on the wall”, they exhibit greater coping and adaptability (Ayduk \& Kross, 2010).

\section{Purpose of the Study}

Although self-distancing is known to lead to lower aggressive thoughts, reduced angry feelings, less displays of aggressive behaviors, improved interpersonal interactions, increased long-term emotional well-being, and improved physiological health, in studies using samples of adults and even elementary school students, no research is known to exist examining the efficacy of self-distancing on adolescents, a population for which there may be promising educational and mental health implications. The purpose of the present study was to employ an experimental design in a population of high school students to examine the efficacy of self-distancing as an intervention for promoting reflective adaptation to autobiographical anger inducing experiences relative to a control group that was not provided a prompt for the self-distancing perspective. 


\section{CHAPTER II}

\section{REVIEW OF THE LITERATURE}

\section{Historical Perspective on Anger}

It was not until the end of the $18^{\text {th }}$ century that Americans began to value the regulation of anger for the purpose of promoting social harmony (Stearns \& Stearns, 1986). In early Western history, there was no clear consensus on the value of anger. While, generally ancient Greek philosophers expressed hostile attitudes towards anger in society, Aristotle noted that anger has value when it arose to prevent perceived injustices, is a natural method of self-defense when an individual is wronged, and is morally praiseworthy when expressed to an appropriate extent, under appropriate conditions, and in an acceptable form. Traditional Christian morality identified anger as a deadly sin, unless it was the wrath of God. Antithetical to Aristotle's position, Seneca would attribute Roman military superiority to their discipline in combat, which stood in contrast to the fury of the Germans. Inspired by Aristotle, the medieval scholar Aquinas stepped away from the anger as madness and evil perspective and argued that anger, when justified, was not a sin and served the causes of pedagogy and criminal justice. The Enlightenment philosopher David Hume took a radical position on anger by asserting that since anger is an inherent passion, to not express anger reflected poorly on an individual's character and intellect (Fiero, 2005; Hughes, 2001; Kemp \& Strongman, 1995).

The reason for this historical ambivalence of intellectuals towards the examination of anger as a social issue worthy of more than a cursory concern is that anger, although considered a "negative emotion" in the modern context, can play adaptive social functions. For example, research on social emotions suggests that the expression of anger may serve to communicate that a particular issue is imperative to the expresser of anger and that the expresser is unwilling to 
yield in his or her position (Frank, 1988; Fridlund, 1991, 1994; Hinde, 1985; Keltner \& Haidt, 2001; Morris \& Keltner, 2000). Van Kleef, De Dreu, and Manstead (2004) found that participants tended to be more flexible towards an angry opponent than with a happy opponent in negotiating tasks, because participants used emotional information to reach conclusions about the limits of other and matched their demands with those perceived limits. As with other animals, behaviors associated with anger function as warnings to stop a threatening behavior, hence why physical conflicts rarely occur without a prior display of anger (Morris, 1967). Researchers have also noted that displays of anger can be used as tactics for social influence as people expressing anger are seen as dominant, strong, competent, and smart at the expense of appearing less warm, friendly, and nice (Clark, Pataki, \& Conway, 1996; Gallois, 1993; Hochschild, 1983; Labott, Martin, Eason, \& Berkey, 1991; Sutton, 1991).

Some theorists have argued that like all impression management techniques, the ultimate goal of displaying anger is to acquire status and power and is therefore simply an intimidation strategy for gaining immediate compliance, with long-term sustainability of status being questionable (Clark et al., 1996; Jones \& Pittman, 1982). Nevertheless, people tend to believe that individuals with angry facial expressions occupy more powerful and higher social positions than people with sad facial expressions (Keating, 1985). Furthermore, Tieden's (2001) study found that participants were more inclined to support an angry, rather than sad, person because expressing anger creates the impression of competence and being an ability owner, which then motivates people to confer a congruous social position. This link between anger and the attribution of social status relate to Chemtob, Novaco, Hamada, and Smith's (1997) argument that anger may be a means to gain mastery over a situation and suppress feelings of helplessness in the face of a threat, a claim supported by research that angry people tend to express optimistic risk estimates and risk-seeking decision-making, a pattern typically more consistent with those of 
happy people than of fearful people — traits that may be considered leadership qualities in certain contexts.

While the above mentioned findings emphasize the adaptive functions of anger by explaining how anger may help individuals respond to anger evoking events to achieve socially desirable outcomes, other theories recognize that there is a point at which the expression of anger can lead to negative outcomes for individuals and groups. The Dual Thresholds Model of Anger (Geddes \& Callister, 2007) suggests that an organization's norms establish thresholds for the expression of anger: The first (expression) threshold is crossed when an individual expresses anger to people who are able to make a change in the anger provoking situation; the second (impropriety) threshold is crossed when an expression of anger is considered by the organization as socially/culturally inappropriate. Negative outcomes occur when 1) anger is suppressed enough to not cross the first threshold, leaving individuals capable of changing the anger provoking condition unaware that someone is being angered by the status quo; 2) anger expression crosses the second threshold and the expresser is deemed 'deviant', increasing the risk of facing sanctions. Once again, when anger is expressed in a way found appropriate by members of an organization, it may start a constructive exchange that resolves concerns. This is consistent with Tieden's (2000) findings that while anger could decrease productivity and increase job stress it could also increase worker motivation, improve relationships, and increase mutual understanding within an organization.

\section{The Cost of Anger}

Despite the potential to harness anger as a source of information to guide decisions to create adaptive changes in an individual's social milieu, undesirable consequences occur when anger is expressed inappropriately. Perhaps the greatest danger of anger lies in that it often 
persists beyond the eliciting situation, guides behavior and cognition in goal-directed ways in response to objects or events that may not even be related to the cause of anger (Gasper \& Clore, 1998; Goldberg, Lerner, \& Tetlock, 1999; Lerner, Goldberg, \& Tetlock, 1998; Raghunathan \& Pham, 1999; Weiner, 1986), creates hostile impulses that interfere with thought (Silverman, 1983), and precipitates negative consequences for those who display anger and engage in aggressive behavior - a common consequence of anger (Buss, 2005). Anger is often of great social cost to others and is considered a contributing factor in violence (Howells, 2012): Anger fosters partner abuse and assault (Schumacher, Feldbau-Kohn, \& Hayman, 2001), plays a role in road rage (Parker, Lajunen, \& Summala, 2002), and has a causal role in 35\% of homicides (Curtis, 1974). Anger related aggression may lead to social disapproval, moral stigmas, and legal difficulties for the aggressor. Furthermore, anger itself costs the individual time and effort wasted on rumination (Sukhodolsky, Golub, \& Cromwell, 2001), increases the risk for hypertension (Rutledge \& Hogan, 2001), coronary heart disease (Tennant \& McLean, 2001), and chronic hostility.

Compounding the risk factors associated with anger, as noted by Mauss, Cook, Cheng and Gross (2007), is the fact that anger is an emotion that requires both daily regulation and is notoriously difficult to regulate. DeFoore (1991) has likened anger to a pressure cooker which can only apply pressure against anger until it inevitably explodes. The suppression of anger may have harmful effects, such as physical symptoms, making the eventual expression of anger more extreme (Kemp \& Strongman, 1995). Historical examples of suppressed anger being released as displaced explosive violence include the 1992 Los Angeles riots and the Nazi scapegoating of the German Jewish population (Fiero, 2005). Neuroscientific research suggests that upon provocation, prefrontal regions of the brain, associated with top-down control over anger and aggressive urges generated by limbic and subcortical regions, increase activity (Davidson, 
Putnam, \& Larson, 2000; Denson, 2011; Denson, Pedersen, Ronquillo, \& Nandy, 2009; Raine, 2008; Siever, 2008). Typically, individuals are motivated to regulate anger and aggressive impulses and physiological arousal is known to dissipate within 10 to 15 minutes, suggesting people are usually capable of effective anger regulation (Doob \& Climie, 1972; Fridhandler \& Averill, 1982; Tyson, 1998). However, the fact that individuals are often unable to succeed in regulating their anger suggests that there are other mechanisms involved which may increase anger and aggression.

One of the obstacles to regulating anger is that the expresser tends to have inaccurate thoughts due to loss of objectivity and self-monitoring capacities. This is why many individuals, when angered, are convinced of their attributions, even when they are mistaken (Novaco, 2000). Unlike with negative emotions, such as sadness and fear, which promote analytical thinking, anger is more likely to make an individual demonstrate correspondence bias, rely on stereotypes, and pay less attention to details, and focus more on the superficial. Studies using neuroimaging to examine the brain of individuals experiencing anger note that anger activates regions of the lateral orbitofrontal cortex, associated with approach motivation and positive affective processes (Litvak, Lerner, Tieden, \& Shonk, 2010). Anger generally makes people think more optimistically: The threat of danger seems smaller, risks seem less likely, the likelihood of success seems higher, and the likelihood of unfortunate events seems less likely. This is exemplified in Lerner and Keltner's (2001) study in which participants primed to feel anger felt less likely to suffer from heart disease and more likely to receive a pay raise than fearful people. People who are angry also anticipate anger causing events by expecting them to occur at a higher rate (DeSteno, Petty, Wegener, \& Rucker, 2000). Anger can also cause people to think more prejudicially and negatively about outsiders (DeSteno, Dasgupta, Barlett, \& Cajdric, 2004). 
Of particular concern in this analysis are anger-inducing interpersonal provocations, actions or situations involving an alleged transgressor or transgressors that are perceived by a victim to be aversive or stressful (Berkowitz, 1984, 1989, 1990, 1993; Carlson \& Miller, 1988; Dollard et al., 1939; Geen, 1990; Huesmann, 1998). Interpersonal provocations are a common and robust antecedent of aggression and arguably the greatest cause of human aggression (Anderson \& Bushman, 2002). As Bettencourt, Talley, Benjamin, and Valentine (2006) have noted, provocations have been operationalized as physical provocations (Bushman, 1995; Giancola \& Zeichner, 1995b; Taylor, 1967); monetary or point penalties during a competitive task (Bjork, Dougherty, \& Moeller, 1997; Bjork et al., 2000); verbal provocations (Berkowitz, 1960; Caprara, Passerini, Pastorelli, Renzi, \& Zelli, 1986; Caprara \& Renzi, 1981); and frustration, such as failure to complete a task or inability to participate in an activity (Geen, 1968; Josephson, 1988; Rule \& Percival, 1971).

\section{Anger in Children and Adolescents}

In recent years, the issue of anger and aggression in children and adolescents has received attention as a major public health problem (Blake \& Harmin, 2007). While anger has been argued to have the positive potential to encourage change in anger inducing situations (Gaylin, 1984; Novaco, 1976; Lerner, 1985; Tavris, 1982), Mahon, Yarcheski, and Yarcheski (2000) found that anger tends to reduce vigor in adolescents. It is also linked with weight loss, increased blood pressure, sleep disturbance, withdrawal, confusion, aches, pains, anorexia, and gastrointestinal upsets (Freeberg, 1982; Hauber, Rice, Howell, \& Carmon, 1998; Larson \& Kasimatis, 1991). Anger in adolescents is also more intense and a dominant experience in their lives (Blanchard-Fields \& Coates, 2008; Spielberger, 1996; Spielberger, Jacobs, Russell, \& Crane, 1983; Wilde, 1996). One source of anger that is unique to this developmental period is 
sensitivity to frustration with rules imposed by the structures of school and home as they are perceived to limit the general sense of independence and inhibit the achievement of social goals. Parental psychological control has also been indirectly linked to adolescent aggressive behavior through anger regulation by frustrating adolescent need for autonomy and intervening in the individuation process (Barber \& Xia, 2013; Steinberg, 2005). Interestingly, longitudinal research (Kollar, Groer, Thomas, \& Cunningham, 1991) and meta-analysis (Archer, 2004) have found no difference in anger between male and female adolescents, with the exception that males were more likely to be perceived to engage in physical aggression and be voted by peers as more aggressive. Anger scores also remained stable between freshman and senior year of high school (Kollar, Groer, Thomas, \& Cunningham, 1991).

Like adults, adolescent anger is linked with irrational beliefs that predict self-reported aggression (Fives, Kong, \& Fuller, \& DiGiuseppe, 2011). More specifically, research on hostile attributions, social problem solving deficits, self-efficacy, outcome expectations, and outcome values support the link between cognition, anger, and reactive and proactive aggression in children and adolescents (Boldizar. Perry, \& Perry, 1989; Crick \& Dodge, 1989; Dodge, 1980; Dodge, Price, Bachorowski, \& Newman, 1990; Joffe, Dobson, Fine, Marriage, \& Haley, 1990; Keltikangas-Jorvinen \& Kangas, 1988; Lochman \& Dodge, 1994; Matthys, Cuperus, \& Van Engeland, 1999; Richard \& Dodge, 1982; Slaby \& Guerra,1988; Steinberg \& Dodge, 1983; Webster-Stratton \& Lindsay, 1999).

As with adults, interpersonal experiences are common triggers of anger with children, which in turn are linked to negative outcomes such as aggression, violence, and depression (Dodge, 1993; Hanish et al., 2004; Huesmann, 1998) as well as social rejection and negative peer reactions (Coie, Dodge, \& Coppotelli, 1982; Fabes, Eisenbeng, Smith, \& Murphy, 1996). If children are also aggressive, they are also perceived by other children to be less deserving of 
sympathy, more deserving of anger, and receive internal-stable attributions regarding their anger (Graham \& Hoehn, 1995). In other words, children are likely to think of an aggressive child as being fundamentally emotionally unstable by nature, not likely to change in the near future, and deserving of retribution.

While these findings appear to be consistent with the research regarding the relationship between anger, aggression, and violence in adults, the most tragic aspect of anger in youth is our knowledge that anger in children and adolescents, untreated, predicts future high risk behaviors such as smoking, drinking, substance abuse, long-term aggression that may pose a risk to the school environment, difficulties with peer relationships, poor educational outcomes, school dropout, and other antisocial behaviors (Agnew, 1985; Grogger, 1997; Kazdin, 1995; Kupersmidt \& Coie, 1990; Mahaded, Bryant, \& Botvin, 2008; Mazerolle et al., 2000; Mazerolle \& Piquero, 1997; Moffitt, 1993; Moss \& Kirisci, 1995; Nichols, Patterson, Forgatch, Pope \& Bierman, 1999; Yoerger \& Stoolmiller, 1998).

In contrast to the outcomes observed in adolescents with uncontrolled anger, adolescents with optimal regulation are able to modulate the occurrence, form, intensity, and duration of emotions in order to accomplish a goal (Eisenberg \& Morris, 2003; Thompson, 1994), and appear to experience psychosocial and physiological benefits. Well regulated adolescents are more socially competent, high in empathy, high in prosocial behavior, low in adjustment difficulties, and low in behavior problems (Eisenberg \& Fabes, 2006). Emotion regulation seems to also increase resilience by protecting children from the effects of negative parenting and parental psychopathology. With such divergent outcomes resulting from the different levels of anger and aggression, it is not surprising that school administrators, teachers, and parents are eager to seek out interventions to address risk factors for aggressive behavior and thereby improve the school environment (Tobin \& Sprague, 2000). 


\section{Treatment}

Perhaps the most research-based treatments for anger are based on cognitive behavioral approaches. The theory behind these treatments often highlight cognitive processes such as attributions, expectations, beliefs, and problem solving strategies, as the most influential determinates of responses to provocations, with anger playing a mediating role between the trigger and aggressive behavior (Feindler \& Engel, 2011). While there are many types of CBT methods, they generally consist of relaxation skills to control arousal, skills to exercise cognitive controls on attention, thoughts, images, and feelings, and understanding provocations as a process. Cognitive therapy has been found to be effective in lowering trait anger, reactivity to potential provocations, most angering situations, daily anger, physiological arousal, anger suppression, and negative expression for up to 15 months (Deffinbacher, Dalen, Lynch, Morris, \& Gowensmith, 2000). Results from meta-analyses suggest that that many cognitive behavioral approaches are effective for anger reduction (Beck \& Fernandez, 1998; Trafrate, 1995). Also, as previously mentioned, a meta-analysis of CBT on both adults and adolescents found a mean weighted effect size of .70 in the reduction of anger (Beck \& Fernandez, 1998).

Despite evidence for the benefits of cognitive behavioral therapies in reducing anger and anger related problems, these interventions require an extensive investment of time, access, and resources. Even a relatively short treatment plan may require around nine weekly sessions, with each session being an hour long. Therapists leading the sessions may also require extensive professional development prior to implementing the interventions (Deffinbacher, Dalen, Lynch, Morris, \& Gowensmith, 2000).

Upon considering factors such as attrition and readiness along with time and resources, it becomes evident that there is a niche for quicker anger interventions. A quick intervention not 
only requires less time, but also less motivation, commitment, psychological resources from the client, and poses a lower risk of attrition (Howells \& Day, 2003).

\section{Limits of Popular Interventions}

Recent research has also brought to light a commonly overlooked issue related to common anger interventions: the questionable effectiveness of self-immersion/reflection procedures found in many therapies. Clinical theory, research, and practice often assume that there are important physical and mental health benefits for individuals who regulate emotions by reflecting upon and working through negative emotions (Greenberg, 2002; Pennebaker, 1997; Pennebaker \& Graybeal, 2001; Rachman, 1981; Stanton, Kirk, Cameron, \& Donoff-Burg, 2000; Wilson \& Gilbert, 2008). Novaco (1975) has argued that in order to manage anger, the situation leading to the anger should be explored. The assumption behind seeking explanations for negative experiences is to provide individuals with closure and emotional relief. Nevertheless, there is contradictory evidence indicating that individuals' attempts to reflect upon their feelings can trap them in a cycle of rumination which aggravates the severity of negative feelings (NolenHoeksema, Wisco, \& Lyubomirsky, 2008).

Baumeister and Heatherton (1996) explain this seemingly counterintuitive observation with a strength (limited resource) model of self-regulation of regulatory failure. In this model, they argue that regulatory failure, the inability to override unwanted thought, feeling, or impulse, results either as a consequence of 1) under-regulation due to deficient standards, inadequate monitoring, or inadequate strength or 2) misregulation due to false assumptions or misdirected efforts, especially unwarranted emphasis on emotion. Self-reflection/immersion fails because it is based on a misunderstanding of contingencies and attempts to control the uncontrollable by prioritizing affect in the process of regulation. This self-focused attention toward one's thoughts 
and feelings becomes provocation-focused thought or rumination (Lyubomirsky \& NolenHoeksema, 1995).

Rather than facilitate regulation, Miller, Pederson, Earleywine, and Pollock (2003) argue that rumination maintains the cognitive representation of the state generated by a provocation even though initial physiological arousal has dissipated. More specifically, rumination can maintain anger (Martin \& Tesser, 1989; Nolen-Hoeksema, 1991; Nolen-Hoeksema, 2000; Rusting \& Nolen-Hoeksema, 1998; Teasdale, 1988). In one study, self-reflection/immersion is even suggested to reduce self-control and increase anger (Denson, Pedersen, Friese, Hahm \& Roberts, 2011). This assertion is supported by studies in which people who self-reflect/immerse in the process of analyzing a provocation re-experienced or relived the negative thoughts, feelings, and physiological sensations (Ayduk \& Kross, 2008; Kross \& Ayduk, 2008; Kross, Ayduk, \& Mischel, 2005). A series of studies by Bushman, Bonacci, Pedersen, Vasquez, and Millier (2005) found that participants asked to ruminate over a provocation were more likely than self-distracting peers to displace aggression on innocent targets. In fact, several studies indicate that people tend to spontaneously adopt a self-immersed perspective when they reflect on their feelings, suggesting that it is the default strategy used by most individuals (Ayduk \& Kross, 2010; Grossmann \& Kross, 2010; Mischikowshi, Kross, \& Bushman, 2012).

Studies exploring alternatives to rumination have found that distraction, moving attention away from an upsetting event and focusing it on unrelated content, is less likely to maintain sad mood for depressed individuals (Morrow \& Nolen-Hoeksema, 1990) and is less likely to maintain anger and aggressive behavior than rumination (Bushman, Bonacci, Pedersen, Vasquez, \& Miller, 2005; Rusting \& Nolen-Hoeksema, 1998). Of course, these findings do not imply that distraction is a viable long-term solution to upsetting events. 
As with self-reflection/immersion, Mauss, Cook, Cheng, and Gross (2007) have noted that with other strategies for self-regulation, even if regulation is achieved, it is obtained at a substantial cost to the individual, including maladaptive physiological responses and disrupted social interactions (Davidson et al., 2000a,b; Dembroski et al., 1985; Gross \& Levenson, 1997; Muraven et al., 1998; Polivy, 1998). Thus, each regulation strategy appears to demonstrate a different profile of consequences (Gross, 2001).

\section{Self-Distancing}

In order to identify an effective form of regulation with minimal costs for expressing anger or regulating it, Mauss, Cook, Cheng, and Gross (2007) suggest using a process model of emotion regulation that examines emotions as a sequence of events and individual responses over time (Gross, 2001; John \& Gross, 2004). In this model, Gross (2001) distinguishes between antecedent-focused and response-focused emotion regulation strategies. Antecedent-focused strategies occur prior to full-scale activation of an anger response and are therefore considered the most effective. Of the antecedent-focused strategies, the most researched is cognitive reappraisals in which emotional episodes are interpreted or cognitively transformed in an objective, non-emotional manner. Cognitive reappraisals are an effective and flexible tool to down-regulate even intense negative emotion (Gross, 2001; Ochsner et al., 2004), with individuals frequently using reappraisals reporting greater positive emotion, less negative emotions, enhanced interpersonal functioning and well-being (Gross \& John, 2003). High reappraisers also have reported less anger, less negative emotions (i.e., guilt, sadness, and anxiety), more positive emotion, greater cardiac output and ventricular contractility, and lesser total peripheral resistance (Mauss, Cook, Cheng, \& Gross, 2007). Cognitive reappraisals have 
been used in professions such as bill collection to help bill collectors cope with the emotive dissonance of the job and help detach from debtors (Sutton, 1991).

Based on Cognitive Construal Theory, individuals who use high level construals—more abstract mental models that consist of general, decontextualized features that convey the essence or gist from available information—as opposed to low-level construals—-focus on more concrete, contextual, and incidental details—experience decreased preferences for immediate over delayed outcomes, greater physical endurance, stronger intentions to exert self-control, and less positive evaluations of temptations that undermine self-control (Fujita, Trope, Liberman, \& Levin-Sagi, 2006; Liberman, Sagristano, \& Trope, 2002). A major determinant of what level of construal is activated is the psychological distance of the event or object, with distancing a target on psychological dimensions of time, space, social distance or hypotheticality leading to greater high-level construal (Liberman, Sagristano, \& Trope, 2002). Thus, psychological distance has been found to play a major role in determining adaptive from maladaptive forms of reappraisal (Kross, 2009).

Because emotional autobiographical memories are an important element of emotional well-being, over focus on emotional aspects of negative experiences can lead to psychiatric disorders. Therefore, it is important to be able to focus away from the emotional aspects of memories to maintain optimal cognitive and affective functioning (Denkova; Dolces; \& Dolces, 2014). In experiments in which participants were asked to analyze their feelings regarding a negative autobiographical experience from a self-distanced perspective (i.e., thinking about oneself from the perspective of a "fly on the wall"), relative to a self-immersed perspective or no perspective, led to less emotional and physiological reactivity in the short-term, reduced risk of negative consequences of rumination over time, less recounting of emotionally evocative details, and more reconstruing in ways that promoted insight and closure (Ayduk \& Kross, 2008; Kross 
\& Ayduk, 2008; Kross, Ayduk, \& Mischel, 2005). Similarly, in Ayduk and Kross's (2010) study of spontaneous self-distancing, participants who spontaneously self-distanced while reflecting on negative memories demonstrated less emotional and cardiovascular reactivity, showed more problem-solving behavior and were less likely to reciprocate negativity during conflicts with romantic relationship partners. Unlike with distraction, the beneficial effects of self-distancing persist up to one week and possibly longer (Kross \& Ayduk, 2008). Denkova, Dolces, and Dolces' (2014) study using fMRI data of individuals using a self-distancing strategy recalling unpleasant autobiographical memories found that focusing away from emotions led to decreased self-reported emotional responses and increased engagement of emotion regulation related regions of the brain (ventro-medial prefrontal cortex) and reduced activity in the emotion related regions (amygdala).

Although almost all studies of self-distancing have used adult samples, Kross, Duckworth, Ayduk, Tsukayama, and Mischel, (2011) tested the efficacy of self-distancing on a sample of elementary school students with at-risk behaviors. They found that self-distancing led to reductions in emotional reactivity and reduced blame of others by reconstructing anger inducing events in a way that promoted insight and closure across race, gender, and SES. Their findings offer promise that self-distancing may be a quick universal intervention that can be applied to other at-risk young populations.

\section{Purpose of the Study}

As self-distancing has been found to lead to reduce aggressive thoughts, angry feelings, aggressive behaviors, improve interpersonal interactions, long-term emotional well-being, and physiological health, there are many potential implications for education and for mental health professionals working with adolescent populations if self-distancing can be found effective with 
this age group. The purpose of the study is to employ an experimental design in a population of high school students to examine the efficacy of self-distancing as an intervention for promoting reflective adaptation to recall of anger inducing events relative to a control group that will not be provided a prompt for the self-distancing perspective. It is hypothesized that after recalling a past interpersonal conflict involving anger, participants who undergo the self-distancing treatment will report less implicit aggression, anger, and less general negative affect than their peers in the control group who will not receive a treatment. 


\section{CHAPTER III}

\section{METHOD}

\section{Participants, Setting, and Recruitment}

Participants in this study were a sample of 26 high school students between the ages of 14 and 17 recruited from a population of 510 students in a middle-class suburban high school. The median family income in the community was approximately $\$ 44,512$ and the student population was approximately $86 \%$ White, $6 \%$ Asian, $4.5 \%$ Hispanic, with English being the primary language for approximately $98 \%$ of the students.

Recruitment. Potential participants were recruited from the entire student body of the high school. During their homeroom period, all students at the school were given a recruitment flyer (see Appendix B) outlining basic study procedures, inclusion/exclusion criteria, benefits/compensation (i.e., movie passes and the chance to win a tablet through a lottery), and a request for parent/guardian contact information if they were interested in having their children participate in the study. Potential participants were asked to turn this form into a special box in the school main office for the experimenter to collect. Parents of students who turned in recruitment flyers were contacted individually via telephone to be informed about the specific details of the study's purpose and procedures, including procedures in which the child will experience incomplete disclosure, as well as the risks and benefits of participation (See Appendix C) for Parental Recruitment/Parent Information Phone Call Script). If parents indicated interest in participation after the phone call, they were mailed Parent Permission Forms (See Appendix D) to sign and return to experimenters using an enclosed return envelope.

School administrators, including an assistant principal, grade level counselors (12 altogether), and school psychologist, who have knowledge of study procedures and potential risks then reviewed the selection of students to exclude students determined to meet exclusion 
criteria. Investigators were available via email and phone before and after the experiment to address any questions or concerns.

Thirty-three students expressed initial interest in participating in the study. No students met criteria exclusion. Of these 33 students, 3 had parents that either 1) could not be reached prior to the experiment or 2) did not return parent permission forms on-time to have their children participate in the study. Of the remaining 30 students, three students were absent on the day of the experiment and one arrived after the initiation of experimental procedures and was too late to participate.

Exclusion Criteria: Students had to be between the ages of 14 to 17 years old and not have 1) visual/ auditory/ reading difficulties that might interfere with understanding and complying with procedures or 2) severe anger, aggression, frustration, or anxiety that might be aggravated and lead to a disruption of study procedures or later academic instruction. These exclusion criteria were delineated in the recruitment flyer and were again reiterated to parents during the telephone communication and in the Parent Permission Form. Upon receiving signed Parent Permission forms, a team of reviewers, made up of the assistant principal, school psychologist, and grade level counselors met as a team to review the list for students that did not meet these criteria. For students identified with a reading disability, reading level was determined to be at least at a $7^{\text {th }}$ grade level, the level at which instructions and forms are comprehensible with adult support. Based on their knowledge of the study procedures, exclusion criteria, and potential risks, reviewers were given the authority to exclude particular students if they determined the their participation in the study would pose a greater risk to that student or the school than any potential benefit of participation in the study. Eighteen year old students were excluded as they have already been represented in previous studies with adult samples. No students were excluded in this process. 
Setting. The experiment took place in a sound-proof lecture hall of a high school with desks and pencils for participants. A neighboring room was used as a waiting area. There was a desk for the experimenters to monitor participants as well as an audio player with speakers.

\section{Procedures and Variables}

Introduction. Prior to initiation of study procedures, half of the participants were randomly assigned to one of two treatment groups (control group or self-distancing group) using a random number generator. On the morning of the experiment, participants were informed/ reminded of their participation in the study through a memo delivered to their homeroom, including directions for where to go when called for participation. Participants were called from their respective classes to the waiting room. When participants in the self-distancing group were called into the experiment room, participants in the control group were supervised by an experimenter. The control group was escorted into the experiment room upon completion of experimental procedures with the self-distancing group. Upon entering the experiment room, participants were given a Participant/Child Assent Form (see Appendix E) and told that experimenters are studying anger in adolescents. Assent forms did not have a detailed explanation of study purpose, no mention of the hypothesis, and the treatment so that participants were able to respond naturally to the experimental manipulation and so they did not feel compelled to give biased responses on questionnaire forms. However, the assent form did explain the experimental manipulation. The actual purpose of the study and hypothesis was to be presented in the debriefing. Because the treatment and the intervention could not be described prior to experimental procedures, the potential benefits of the treatment could not be described until the debriefing (See Appendix $\mathrm{H}$ ) in which they were explained to all participants, including 
the control group. A basic outline of procedures and explanation of potential risks/benefits were outlined in both Parent Permission and Participant Assent forms. Participants were also informed of their rights to privacy of data collected and the right to terminate participation at any time. They were also informed that if they continue to feel stressed or upset after the study, school mental health professionals would be made available to them. Participants were informed that if they wished to be excused for any reason, including using the restroom or seeing a counselor, they could raise their hand and an experimenter would approach them. Participants could then discreetly write a reason for being excused and they would be dismissed by the experimenter. No participants reported distress or sought dismissal.

Experimental manipulation. Participants were told that the first task involves recalling a time when you were angry with someone. Through the audio device, participants were instructed to close their eyes and "Recall an interpersonal experience in which you felt overwhelming anger and hostility.",

Self-perspective task. After a minute, participants were given additional instructions via audio device. Participants assigned to the control group were told to "Go back to the time and place of the experience you just recalled and see the scene in your imagination. Now see the situation unfold through your own eyes as if it were happening to you all over again. Replay the event as it unfolds in your imagination through your own eyes." Participants in the selfdistancing group were told, "Now close your eyes. Go back to the time and place of the experience you just recalled and see the scene in your imagination. Now take a few steps back. Move away from the situation to a point where you can now watch the event unfold from a distance and see yourself in the event. As you do this, focus on what has now become the distant you. Now watch the situation unfold as if it were happening to the distant you all over again. Replay the event as it unfolds in your imagination as you observe your distant self." 
(Kross et al., 2011). Next, all participants were instructed to analyze their emotions for 45 seconds, while maintaining their initial perspective.

Implicit aggressive cognition. After 45 seconds, participants were asked to complete measures of implicit aggressive cognition, (see Appendix F) anger, and negative affect (see Appendix G). We measured the accessibility of aggressive cognitions using a 21-item word completion task (Kross et al., 2005). Seven stems were completed using either neutral or aggression words (e.g., the stem M_D can be completed as MAD or MUD). We counted the number of stems completed with aggression words.

Anger. We focused on angry feelings because it was the target emotion our provocation was designed to elicit. The measure of anger consisted of items rating anger, irritability, hostility and annoyance that are embedded among filler items. Participants completed the valence subscale of the Self-Assessment Manikin (SAM, Bradley \& Lang, 1994) to rate how "angry," "irritable," "hostile," and "annoyed" they feel right now $(1=$ Very slightly or not at all; $5=$ Extremely), along with several filler items. We selected these items a priori and combined them into an anger measure. The internal consistency reliability for this anger measure was 0.89 (Mischkowski, Kross, \& Bushman, 2012). The internal consistency reliabilities for the relevant SAM valence subscales ranged from 0.96 to 0.99 (Bradley \& Lang, 1994).

Negative affect. Also embedded with the Anger items, was the Negative Affect subscale of the Positive and Negative Affect Schedule (PANAS). The internal consistency reliabilities for the relevant Negative Affect subscales range from 0.84 to 0.88 (Watson, Clark, \& Tellegan, 1988).

Debriefing procedures. Upon completion of all scales, the participants in the control group were played the self-distancing script and given 45 seconds to analyze their emotions in order to ensure equal access to the treatment expected to be most efficacious. After completing 
all experimental procedures all participants received a letter of debriefing (see Appendix I). The debriefing included 1) an expression of appreciation for participation in the study, 2) an explanation of the true purpose of the study, 3) an explanation of the procedures, 4) an explanation for why participants were not fully informed about the purpose of the study, treatments, and measures, 5) the potential benefits of this study on the development of the field of anger research and psychoeducational services, as well as a suggestion for the personal application of self-distancing for dealing with anger, and 6) the contact information of the primary investigator in case there are any questions or concerns. An experimenter verbally reviewed these six major elements of the debriefing letter and welcomed questions at this time and after the experiment. Participants were then be thanked for their participation, received compensation (movie pass), and the iPad Mini raffle winner was announced. Furthermore participants were informed that if they still feel angry, agitated or upset, they could request to see a counselor.

Data analysis plan. Data were analyzed using the Hotelling's $\mathrm{T}^{2}$ procedure (a special case of the multivariate analysis of variance procedure when there are two comparison groups) to compare the no perspective control group and the self-distancing experimental group on the variables (implicit aggressive cognition, anger, and negative affect). The effect sizes of the treatment on all the dependent variables were examined by computing the Mahalanobis Distance between the two groups. 


\section{CHAPTER IV}

\section{RESULTS}

Data were collected from 26 participants (13 in each group), 11 males and 15 females, representing grades 9 through 12 . There were no instances of missing data on the PANAS scale. Twenty-one of the 26 participants were able to complete all seven of the incomplete stems in the implicit aggressive cognition task. The other five participants completed six out of the seven of the stems with each participant having skipped the same item, two of whom were in the control group and three from the self-distancing group. In order to use a consistent scale across participants, despite the differences in number of completed items, completed stems were converted into a percentage of stems completed as aggressive words over the number of all potential aggressive stems. For descriptive statistics, see Table 1.

\section{Multivariate analysis}

The results of the multivariate analysis did not demonstrate a significant multivariate effect for differences between groups across all dependent variables (Hotelling's $T^{2}=2.904 ; F(4$, 21) $=0.637, \mathrm{p}=0.642)$. The Mahalanobis distance was 0.45 .

t-test

For Implicit Aggressive Cognition, an independent sample $t$ test showed that the difference between the self-immersion control group $(n=13, M=50.62, S D=19.85$, CI [62.61, 38.62] $)$ and the self-distancing group $(n=13, M=56.77, \mathrm{SD}=18.31,95 \%$ CI $[67.84,45.7])$ was not statistically significant, $t(24)=-0.82, p=0.42, d=-0.32$ and the observed effect size small. 
For Anger, an independent sample $t$ test showed that the difference between the selfimmersion control group $(n=13, M=8.92, S D=4.29, \mathrm{CI}[11.51,6.33])$ and the self-distancing group $(n=13, M=9.46, S D=4.72,95 \%$ CI $[12.31,6.61])$ was not statistically significant, $t(24)$ $=-0.3, p=0.76, d=-0.12$ and the observed effect size negligible. The scores on the four anger items that comprised this scale were strongly correlated, $\alpha=0.91$.

For Negative Affect, an independent sample $t$ test showed that the difference between the self-immersion control group $(n=13, M=19.54, S D=7.88$, CI $[24.36,14.72])$ and the selfdistancing group $(n=13, M=22.46, S D=9.96,95 \%$ CI $[28.48,16.44])$ was not statistically significant, $t(24)=-0.83, p=0.417, d=-0.32$. The scores on the ten items that comprised the Negative Affect scale were strongly correlated, $\alpha=0.91$. However, after removing anger items from the Negative Affect scale the difference between the self-immersion control group $(n=13$, $M=11.31, S D=5.49, \mathrm{CI}[14.63,7.99])$ and the self-distancing group $(n=13, M=12.23, S D=$ $5.31,95 \%$ CI $[15.44,9.02])$ was not statistically significant, $t(24)=-0.44, p=0.67, d=-0.17$ and demonstrated a small effect size, suggesting that participants experiencing the self-distancing treatment may not have experienced any less negative emotions excluding anger than the control and may have even experienced slightly more negative emotions compared to the control group when excluding anger as a negative emotion. The scores on the seven items that comprised the Negative Affect scale without items related to Anger were also strongly correlated, $\alpha=0.892$. 


\section{CHAPTER V: DISCUSSION}

The goal of this study was to examine potential efficacy of self-distancing in reducing anger and general negative affect in a sample of high school students. Because previous research on adults and at-risk children has demonstrated the utility of this quick and easily implemented intervention to reduce anger, aggressive thoughts, aggressive behavior, and symptoms associated with depression, it appeared to offer promise for the adolescent population. The adolescent population is considered in need of anger interventions because of their increased vulnerability to intense feelings of anger and aggressive behavior. Thus, this line of research has important implications for education and mental health professionals that work with this population.

While it was hypothesized that after recalling a past interpersonal conflict, adolescent participants randomly assigned to experience the self-distancing treatment would report less implicit aggression, less anger, and less negative affect than similar participants assigned to the self-immersion control group, the results consistently indicated that self-distancing did not reduce implicit aggression, anger, or negative affect. Contrary to the hypothesis, self-distancing appeared to have a small to moderate effect size $(d=-0.32)$ in the negative direction for Implicit Aggressive Cognition, suggesting that the self-distancing intervention may have increased levels of subconscious aggressive thought. For Anger, self-distancing had a small negative effect size $(d=-0.12)$, reflecting a small increase in self-reported levels of anger. Similar to Implicit Aggressive Cognition, self-distancing appeared to also lead to a small to moderate increase $(d=$ 0.32) in self-reported Negative Affect. The effect size decreased to a small level $(d=-0.17)$ when items related to self-reports of anger were removed from the analysis, suggesting a considerable proportion of the negative affect experienced by participants in the self-distancing group is attributable to an increase in anger. The disproportionate increase of Implicit 
Aggressive Cognition relative to Anger may suggest that the self-distancing treatment directly affected cognition, which mediates the relationship between anger and aggression. It could also reflect the large impact of small increases in anger on aggressive cognition in adolescents.

While results that indicated the effectiveness of self-distancing in reducing anger and negative emotion would have opened the door to potential utilization as an effective and quick universal intervention for reducing adolescent anger and negative affect, finding contrary evidence also raises interesting questions as this sample of adolescents is the first to fail to respond to self-distancing. It also raises the potential concern that adolescents in general may not respond positively to this intervention.

One older avenue of research that has recently regained popular interest and may be of use in explaining why self-distancing did not work for this adolescent sample is the concept of adolescent egocentrism. Inspired by Piaget (1926; Piaget \& Inhelder, 1956), the concept of adolescent egocentrism refers to developmental period specific egocentric behaviors in adolescence including imaginary audience and personal fable. These egocentric behaviors are the result of developmental changes in cognitive and social domains that enable adolescents to process abstract and hypothetical content (Beaudoin \& Schonert-Reichl 2006; Woolfolk, 2010). While the capacity to think about their own thoughts can free a child from object centration, it can also produce a belief that their own concerns are the focus of other people's thoughts, a failure to differentiate between their own thought contents (the subjective) and the thought contents of others, the objective (Artar, 2007; Elkind, 1978; Frankenberger, 2000). While originally believed to characterize early adolescence, it also exists in late adolescence and may exert a powerful influence when individuals enter novel environments and situations (Alberts, Elkind \& Ginsberg, 2007; Schwartz, Maynard \& Uzelac, 2008). 
Of the two elements of adolescent egocentrism that are of concern to this discussion, imaginary audience refers to the mistaken belief that others are constantly watching, monitoring, and criticizing them, perhaps even talking behind their back (Vartanian, 2001). Because adolescents are often preoccupied with themselves, they make the false assumption that others are just as focused on them (Elkind, 1967, 1978, 1985). Thus, egocentric adolescents may feel they are being singled-out by a teacher, that their peers are noticing their mistakes, and that their accomplishments are of utmost importance to others (Bester, 2013). In terms of self-distancing, this may have led to adolescent participants not being able to effectively focus on the context of the situation being recalled. Even if they are looking at their autobiographical memories from the perspective of an outsider, they may assume the position that an outsider would evaluate the situation the same way, if not similarly. Worse, it may even increase the experience of anger by adding an element of public humiliation.

The experience of humiliation through social evaluation may explain the increase in negative emotions found in the self-distancing group. The Negative Affect scale is loaded with multiple anxiety-related emotions: nervous, upset, distressed, guilty, scared, jittery, and afraid. These emotions all relate to symptoms of anxiety. It is possible that when adolescents selfdistance, their tendency for imaginary audience enhances feelings of evaluation apprehension or other forms of social anxiety, which mediate the self-reported Negative Affect. This could explain the increase in negative affect independent of the increase in anger.

The second element of adolescent egocentricity that may play a role in undermining the effectiveness of self-distancing in reducing anger and negative emotions is personal fable. Personal fable refers to the unrealistic belief in one's uniqueness and unlimited capabilities, which lead to adolescents believing that their feelings and experiences are so unique and intense 
that they are beyond the comprehension of others (Bright, McKillop, \& Ryder, 2008; O'Conner, 1995). One of the challenges caused by personal fable in pedagogic and therapeutic settings is that adolescents may think that their situation is so unique that proven strategies may not apply to them and therefore nobody can advise them. In the process of attempting to self-distance, an adolescent's personal fable may neutralize any of the benefits attained through focus on context and reinforce cognitions about the uniqueness of specific emotional content. After all, if your experiences are beyond the comprehension of others, an objective perspective is then either meaningless or can only be interpreted the same way as it would be interpreted from the subjective perspective. Related to the personal fable and the belief that rules and strategies do not apply is a sensitivity to and frustration with rules and structures that are perceived to limit a general sense of independence and the achievement of social goals. If the anger inducing event recalled by an adolescent involves frustration resulting from the inability to fulfill a need for autonomy due to the contextual restraints of the situation, then self-distancing, which benefits individuals by having them focus on a greater context, may not serve a therapeutic function and may reinforce the frustration of having been stifled in the desire to achieve autonomy.

The possible impact of these developmental phenomena requires examination in future studies of adolescents using cognitive construal interventions. One possibility is that because the pull of egocentrism is strong, a clearer prompt that specifically outlines what emotions and thoughts to analyze during the self-distancing task is necessary to emphasize the importance of maintaining a distant focus. While the self-distancing and self-immersion prompts used in this study were based on Kross, Duckworth, Ayduk, Tsukayama, \& Mischel's (2011) prompt for an elementary school sample, such a script may have been overly simplified for adolescents who have much more complex cognitive capacities. As such, future studies should consider the 
inclusion of the following script taken from Ayduk and Kross (2008, p. 229), a study on selfdistancing in a diverse sample of undergraduate university students, after the initial selfdistancing prompt: "As you continue to relive this conflict, try to understand the emotions that you [your distant self] experienced as the conflict unfolded. Why did you [he/she] have those feelings? What were the underlying causes and reasons?"

Initial studies on the effectiveness of self-distancing also used written narrative tasks to examine the extent to which individuals re-construed their recalled experiences in abstract versus concrete terms, which they found to mediate the effectiveness of self-distancing. After the recall and self-distancing task, Kross, Adyuk, and Mischel (2005) had participants describe their stream of thoughts during the task in writing. Two independent judges blind to the experimental condition than rated the essays on the extent to which they reflected concrete construals ("what" statements that describe the specific chain of events, behaviors, or emotions experienced; and blame/fault attributions) or abstract construals (metacognitive insight statements that describe a realization about or change in the way participants understood the causes of the event and the feelings of both parties involved; and metacognitive closure statements that indicated assessment of the situation from a broad perspective to, including past and current experiences, to make sense of the event). In another study by Ayduk and Kross (2010), after participants completed a manipulation check that asked the extent to which they saw the event replay through their own eyes versus watched the event unfold as an observer and how far away from the scene they were, participants completed closed-ended questions that explored recounting/concrete construals versus reconstruing (context construal). Items included statements such as "My thoughts focused on the specific chain of events—-sequence of events, what happened, what was said and done-as I thought about the experience in the study," "As I thought about my experience during 
the study I had a realization that caused me to think differently about the experience," "As I thought about my experience during the study I had a realization that made me experience a sense of closure," and "Thinking about my experience during the experiment led me to have a clearer and more coherent understanding of this experience." While the focus of the current study was focused more on effectiveness in reducing anger and negative emotion as these theoretical elements had already been well studied and consistent across studies and populations, the failure to find positive effects of self-distancing on adolescents justifies exploration of the cognitive processes activated by this intervention in adolescents.

Another area that may warrants exploration is the effect of self-distancing on levels of adolescent aggression. While anger mediates the relationship between provocations and aggression, and self-distancing has been found to reduce both anger and aggression in child and adult samples, if self-distancing does not reduce aggressive thought, anger, or negative emotions in adolescents, what impact does self-distancing have on actual adolescent aggression? While the answer can be assumed to be that levels of aggression are positively correlated with levels of anger and would therefore not change or may increase in adolescents exposed to a self-distancing treatment, acts of aggressive behavior were not measured in this study because of ethical concerns and the practical incompatibilities of using most measures of aggression. The most popular task used to test aggression, utilized in Michkowski, Kross, and Bushman (2012), and potentially most applicable to this study was the TAP task (Tayler, 1967), which involves participants receiving noxious stimuli, usually electric shock or noise blast, and believing that they are giving another participant the same noxious stimuli. However, ethical concerns of having minors receive physical pain and believe they are also hurting others prevented the implementation of this procedure. Fortunately, measuring aggression may now be possible due 
to a recent avenue of research by DeWall et al. (2013) that has established reliability and validity for the use of the Voodoo Doll Task (VDT) as a measure of aggressive inclinations. Inspired by research on magical beliefs and the law of similarities (Rozin, Millman, \& Nemeroff, 1986), it was proposed that causing harm to an actual or digital voodoo doll by stabbing it with pins has psychological corollaries to causing actual harm to the person the doll is intended to represent. In a typical study, the VDT may involve presenting a doll (actual or computer image) that represents a person involved in an anger/aggression inducing situational manipulation to participants and then telling them that since part of the study may have been negative, they now have the opportunity to release their negative energy by stabbing the doll with as many pins as they wish, with the number of pins indicating the level of aggressive intent a participant has.

\section{Limitations}

Because practical constraints limited the extent to which potential limitations could be addressed, a few notable limitations will be addressed in this section. One notable validity issue is that the sample was a small one from a relatively homogeneous community and only from one school in that community, therefore generalizations based on the obtained results should be limited. For example, the results indicating that self-distancing may have increased implicit aggressive cognition, anger, and negative affect may be the result of an artifact of characteristics particular to this one sample, school, or community, that may not currently be evident and does not apply to the general adolescent population. Likewise, there is also a possibility that since the only research using self-distancing on a population of minors employed the treatment on at-risk elementary school students, self-distancing may only be effective with at-risk adolescents. Further generalizations can only be made under the condition that similar research using larger and more diverse samples reflects the pattern of results in this present study. 
Another issue related to the small sample size is that the study was underpowered.

Statistical power refers to the probability of correctly rejecting the null hypothesis when the null hypothesis is false. In other words, the presence of an effect or significant difference is harder to detect when a sample size is smaller as sample size determines the amount of sampling error in a result. Although changing the statistical significance criterion used and changing the magnitude of the effect of interest in the population can affect statistical power, increasing the sample size is the usually the easiest way to boost the power of a test. While the sample size in this study may have been too small to detect statistically significant differences between the means of the two groups across dependent variables, the effect sizes demonstrate small to moderate increases in thoughts and emotions across dependent variables, which clearly contradicts the expected findings based on previous literature. Nevertheless, in order to increase the number of participants, future research should be conducted in regions with denser populations of adolescents or sample students from multiple sites across a broader region. Future studies should also utilize diverse measures of anger and aggression in order to determine the practical implications of measured changes in anger and aggression on short-term psychological, social, and academic/occupational functioning.

A third concern is the possibility that the time spent waiting for the control group may have somehow increased the implicit aggressive cognition, anger, and negative emotions of the self-distancing group, perhaps due to the time being spent on unpleasant interactions or conversations, frustration with waiting, boredom, and fatigue. While most students sat quietly reading or worked on homework as they waited, this history threat is a valid concern to be explored. Yet, considering that based on previous studies, self-distancing is expected to have a moderate to large effect size on aggressive cognition, aggressive behavior, anger, and negative 
affect, it seems unlikely that simply waiting 10 minutes could have affected aggressive thought, anger, and negative affect enough to create a small to moderate negative effect size. Assuming considerable technological resources are available this issue could be avoided completely by having all participants undergo the entire experiment over computer software or on a tablet app at the same time. This would allow for both groups to undergo the experiment simultaneously and nullify the threat of history. This approach has the added benefit of allowing participants as much time as they need to process the recall and construal tasks.

Lastly, because it was ethically unavoidable to share the nature of the study and details of the study procedures with the parents of adolescent participants, there is a risk that the study may have been contaminated by parents disclosing study purpose and procedures with their children. This was addressed best by first having parents sign a recruitment interest form with a request to speak to the parents of each potential participant individually so that the concern for contamination could be addressed to each parent. On the day of the experiment, all participants had indicated that their parents had not shared the details of the study. The participants also did not seem to be very familiar with each other and did not appear to engage in socializing when given the opportunity so the spread of any potential case of contamination appears unlikely.

\section{Conclusions}

The results of the current investigation raise many unexplored issues with the use of selfdistancing as an intervention for adolescents. While research thus far using various methods have unanimously recognized the efficacy of self-distancing in reducing negative affect and aggressive behavior in adults and children, this is the first study known to explore the use of selfdistancing in adolescents and the first to find the intervention ineffective in reducing aggressive 
cognition, anger, and negative affect. Contrary to the trend in literature that has found a moderate to large effect size for this treatment, this study found self-distancing to increase implicit aggressive cognition, anger, and negative affect with a small to moderate effect size. While there are multiple concerns with the generalizability of these findings, it is safe to say that, at least for this sample of participants, there is still a need for a quick and effective treatment for anger and negative affect. 


\section{References}

Agnew, R., 1985. A revised strain theory of delinquency. Social forces, 64, 151-167.

Alberts, A., Elkind, D., \& Ginsberg, S. (2007). The personal fable and risk-taking in early adolescence. Journal of Youth and Adolescence, 36, 71-76.

Anderson, C. A., \& Bushman, B. J. (2002). Human aggression. Annual Review of Psychology, 53, 27-51.

Archer, J. (2004). Sex differences in aggression in real-world settings: A meta-analytic review. Review of General Psychology, 8, 291-322.

Artar, M. (2007). Adolescent egocentrism and theory of mind: In the context of family relations. Social Behaviour and Personality, 35, 1211-1220.

Ayduk, O., \& Kross, E. (2008).Enhancing the pace of recovery: Self-distanced analysis of negative experiences reduces blood pressure reactivity. Psychological Science, 19, 229231.

Ayduk, O. \& Kross, E. (2010). From a distance: Implications of spontaneous self-distancing for adaptive self-reflection. Journal of Personality and Social Psychology, 98, 809-829.

Barber, B. K., \& Xia, M. (2013). The centrality of control to parenting and its effects. In R. E. Larzelere, A. S. Morris, \& A. W. Harrist (Eds.), Authoritative parenting: Synthesizing nurturance and discipline for optimal child development (pp. 61-87). Washington, DC: American Psychological Association. doi:10.1037/13948-004

Baumeister, R. F., \& Heatherton, T. F. (1996). Self-regulation failure: An overview. Psychological Inquiry, 7, 1-15. 
Beaudoin, K. M., \& Schonert-Reichl, K.A. (2006). Epistemic reasoning and adolescent egocentrism: Relations to internalizing and externalizing symptoms in problem youth. Journal of Youth and Adolescence, 35, 999-1014.

Beck, R., \& Fernandez, E. (1998). Cognitive-behavioral therapy in the treatment of anger: A meta-analysis. Cognitive Therapy and Research, 22, 63-74.

Berkowitz, L. (1960). Repeated frustrations and expectations in hostility arousal. Journal of Abnormal and Psychology, 60, 422-429.

Berkowitz, L. (1984). Some effects of thoughts on anti- and prosocial influences of media events: A cognitive-neo associationistic analysis. Psychological Bulletin, 95, 410-427.

Berkowitz, L. (1989). Frustration-aggression hypothesis: Examination and reformulation. Psychological Bulletin, 106, 59-73.

Berkowitz, L. (1990). On the formation and regulation of anger and aggression: A cognitive neoassociationistic analysis. American Psychologist, 45, 494-503.

Berkowitz, L. (1993). Aggression: Its causes, consequences, and control. New York, NY: McGraw-Hill.

Bester, G. (2013). Adolescent egocentrism in a learning context. Africa Education Review, 10, 393-409, doi: 10.1080/18146627.2013.853537

Bettencourt, A., Talley, A., Benjamin, A. J., \& Valentine, J. (2006). Personality and aggressive behavior under provoking and neutral conditions: A meta-analytic review. Psychological Bulletin, 132, 751-777.

Bjork, J. M., Dougherty, D. M., \& Moeller, F. G. (1997).A positive correlation between selfratings of depression and laboratory-measured aggression. Psychiatry Research, 69, $33-$ 38. 
Bjork, J. M., Dougherty, D. M., Moeller, F. G., \& Swann, A. (2000). Differential behavioral effect of plasma tryptophan depletion and loading in aggressive and nonaggressive men. Neuropsychopharmacology, 22, 357-369.

Blake, C. S., \& Hamrin, V. (2007). Current approaches to the assessment and management of anger and aggression in youth. Journal of Child and Adolescent Psychiatric Nursing, 20, 209-221.

Blanchard-Fields, F., \& Coates, A. H. (2008). The experience of anger and sadness in everyday problems impacts age differences in emotion regulation. Developmental Psychology, 44, $1547-1556$.

Boldizar, J. P., Perry, D. G., \& Perry, L. C. (1989). Outcome values and aggression. Child Development, 60, 571-579.

Bright, S. J., McKillop, D., \& Ryder, D. (2008). Cigarette smoking among young adults: Integrating adolescent cognitive egocentrism with the Trans-Theoretical Model. Australian Journal of Psychology, 60, 18-25.

Bushman, B. J. (1995). Moderating role of trait aggressiveness in the effects of violent media on aggression. Journal of Personality and Social Psychology, 69, 950-960.

Bushman, B. J., Bonacci, A. M., Pedersen, W. C., Vasquez, E. A., \& Miller, N. (2005). Chewing on it can chew you up: Effects of rumination on triggered displaced aggression. Journal of Personality and Social Psychology, 88, 969-983.

Buss, D. M. (2005). The murderer next door: Why the mind is designed to kill. New York, NY: Penguin.

Butler, E. A., Egloff, B., Wilhelm, F. W., Smith, N. C., Erickson, E. A., Gross, J. J. (2003). The social consequences of expressive suppression. Emotion, 3, 48-67. 
Caprara, G. V., Passerini, S., Pastorelli, C., Renzi, P., \& Zelli, A. (1986). Instigating and measuring interpersonal aggression and hostility: A methodological contribution. Aggressive Behavior, 12, 237-247.

Caprara, G. V., \& Renzi, P. (1981).The frustration-aggression hypothesis vs. irritability. Recherches de psychologie sociale, 3, 75-80.

Carlson, M., \& Miller, N. (1988). Bad experiences and aggression. Sociology and Social Research, 72, 155-158.

Centers for Disease Control and Prevention (2013). Web-based injury statistics query and reporting system (WISQARS). Atlanta, GA: National Center for Injury Prevention and Control. Retrieved from: http://www.cdc.gov/injury/wisqars/index.html.

Chemtob, C. M., Novaco, R. W., Hamada, R. S., Douglas, M. G., \& Smith, G. (1997). Anger regulation deficits in combat-related posttraumatic stress disorder. Journal of Traumatic Stress, $10,17-36$.

Clark, M. S., Pataki, S. P., \& Carver, V. (1996). Some thoughts and findings on selfpresentations of emotions in relationships. In G. J. O. Fletcher \& J. Fitness (Eds.), Knowledge structures in close relationships: A social psychological approach (pp. 247274). Mahway, NJ: Erlbaum.

Coie, J. D., Dodge, K. A., \&Coppotelli, H. (1982). Dimensions and types of social status: A cross-age perspective. Development Psychology, 18, 557-570.

Cole, R. L. (2008). A systematic review of cognitive-behavioural interventions for adolescents with anger-related difficulties. Educational \& Child Psychology, 25, 27-47.

Cornell, D. G., \& Loper, A. B. (1998). Assessment of violence and other high-risk behaviors with a school survey. School Psychology Review, 27, 317-330. 
Cramerus, M. (1990). Adolescent anger. Bulletin of the Menninger Clinic, 54, 512-523.

Crick, N. R., \& Dodge, K. A. (1989). Children's perceptions of peer entry and conflict situations: Social strategies, goals, and outcome expectations. In B. Schneider, J. Nadel, G. Attili, \& R. Weissberg (Eds.), Social competence in developmental perspective (pp. 396-399). New York, NY: Kluwer Academic Publishers.

Curtis, L. A. (1974). Criminal violence. Lexington, MA: D.C. Heath.

Davidson, K., MacGregor, M. W., Stuhr, J., Dixon, K., MacLean, D., (2000). Constructive anger verbal behavior predicts blood pressure in a population-based sample. Health Psychology, $19,55-64$.

Davidson, R. J., Putnam, K. M., \& Larson, C. L. (2000). Dysfunction in the neural circuitry of emotion regulation: A possible prelude to violence. Science, 289, 591-594.

Deffinbacher, J. L., Dalen, E. R., Lynch, R. S, Morris, C. D., \& Gowensmith, W. N. (2000).An application of Beck's cognitive therapy to general anger reduction. Cognitive Therapy and Research, 24, 689-697.

Deffenbacher, J. L., Oetting, E. R., Lynch, R. S., \& Morris, C. D. (1996). The expression of anger and its consequences. Behaviour Research and Therapy, 34, 575-590.

DeFoore, W. G. (1991). Anger: Deal with it, heal with it, stop it from killing you. Deerfield Beach, FL: Health Communications, Inc.

Dembroski, T. M., MacDougall, J. M., Williams, R. B., Haney, T. L., Blumenthal, J. A., (1985). Components of Type A, hostility, and anger-in: Relationship to angiographic findings. Psychosomatic Medicine, 47, 219-233. 
Denkova, E., Dolcos, S., \& Dolcos, F. (2014). Neural correlates of 'distracting' from emotion during autobiographical recollection. Social Cognitive and Affective Neuroscience Advance Access, 9, 1-12. doi:10.1093/scan/nsu039

Denson, T. F. (2011). A social neuroscience perspective on the neu-robiological bases of aggression. In M. Mikulincer \& P. R. Shaver (Eds.) Human aggression and violence: Causes, manifestations, and consequences (pp. 105-120). Washington, DC: American Psychological Association.

Denson, T. F., Pedersen, W. C., Friese, M., Hahm, A., \& Roberts, L. (2011). Understanding impulsive aggression: Angry rumination and reduced self-control capacity mechanisms underlying the provocation-aggression relationship. Personality and Social Psychological Bulletin, 37, 850-862.

Denson, T. F, Pederson, M. F., Hahm, A., \& Roberts, L. (2011). Understanding impusive aggression: Angry rumination and reduced self-control capacity anger mechanisms underlying the provocation-aggression relationship. Personality and Social Psychology Bulletin, 37, 850-862.

DeSteno, D., Dasgupta, N., Bartlett, M. Y., \& Cajdric, A. (2004). Prejudice from thin air: The effect of emotion on automatic intergroup attitudes. Psychological Science, 15, 319-324. doi:10.1111/j.0956-7976.2004.00676.

DeSteno, D., Petty, R. E, Wegener, D. T., \& Rucker, D.D. (2000). Beyond valence in the perception of likelihood: The role of emotion specificity. Journal of Personality and Social Psychology 78, 397-416. doi:10.1037/0022-3514.78.3.397 
DeWall, C. N., Finkel, E. J., Lambert, N. M., Slotter, E. B., Bodenhausen, G. V., Pond Jr., R. S., Renzetti, C., M., Fincham, F. (2013). The voodoo doll task: Introducing and validating a novel method for studying aggressive inclination. Aggressive Behavior, 38, 419-439.

DiGiuseppe, R., \& Tafrate, R. C. (2007). Understanding anger disorders. New York: Oxford University Press.

Dodge, K. A. (1980). Social cognition and children's aggressive behavior. Child Development, $51,162-170$.

Dodge, K. A. (1993). Social-cognitive mechanisms in the development of conduct disorder and depression. Annual Review of Psychology, 44, 559-584.

Dodge, K. A., Price, J. M., Bachorowski, J., \& Newman, J. P. (1990). Hostile attributional biases in severely aggressive adolescents. Journal of Abnormal Psychology, 99, 385-392.

Doob, A. N., \&Climie, R. J. (1972). Delay of measurement and the effects of film violence. Journal of Experimental Social Psychology, 8, 136-142.

Eisenberg, N., \& Fabes, R. A. (2006). Emotion regulation and children's socioemotional competence. In L. Balter \& C. S. Tamis-LeMonda (Eds.), Child psychology: A handbook of contemporary issues (2nd ed., pp. 357-381). New York, NY: Psychology.

Eisenberg, N., \& Morris, A. S. (2003). Children's emotion-related regulation. In R. V. Kail (Ed.), Advances in child development and behavior (Vol. 30, pp. 189-229). San Diego, CA: Academic. doi:10.1016/S0065-2407(02)80042-8

Elkind, D. (1967). Egocentrism in adolescence. Child Development, 38, 1025-1034.

Elkind, D. (1978). The child's reality: Three developmental themes. Hillsdale, NJ: Lawrence Erlbaum. 
Elkind, D. (1985). Egocentrism redux. Developmental Review, 5, 218-226.

Fabes, R. A., Eisenbeng, N., Smith, M. C., \& Murphy, B. C. (1996). Getting angry at peers: Associations with liking of the provocateur. Child development, 67, 942-956.

Feindler, E. L., \& Engel, E. (2011). Assessment and intervention for adolescent with anger and aggression difficulties in school settings. Psychology in the Schools, 48, 243-253.

Fiero, J. W. Anger. (2005). Anger. In Ethics - Revised Edition (Vol. 1, pp. 57-58). Pasadena, CA: Salem Press, Inc.

Frank, R. H. (1988). Passions within reason: The strategic role of emotions. New York, NY: Norton.

Frankenberger, K. D. (2000). Adolescent egocentrism: A comparison among adolescents and adults. Journal of Adolescence, 23, 343-354.

Freeberg, S. (1982). Anger in adolescence. Journal of Psychosocial Nursing and Mental Health Services, 20, 29-31.

Fridlund, A. J. (1991). Sociality of solitary smiling: Potentiation by an implicit audience. Journal of Personality and Social Psychology, 60, 229-240.

Fridlund, A. J. (1994). Human facial expression: An evolutionary view. San Diego, CA: Academic Press.

Fridhandler, B., \& Averill, J. R. (1982). Temporal dimensions of anger: An exploration of time and emotion. In J. R. Averill (Ed.), Anger and aggression: An essay on emotion (pp. 253280). New York, NY: Springer-Verlag.

Fujita, K., Trope, Y., Liberman, N., \& Levin-Sagi, M. (2006). Construal levels and self-control. Journal of Personality and Social Psychology, 90, 351-367. 
Gabel, S., \& Shindledecker, R. (1991). Aggressive behavior in youth: Characteristics, outcome, and psychiatric diagnoses. Journal of the American Academy of Child and Adolescent Psychiatry, 30, 982-988.

Gallois, C. (1993). The language and communication of emotion. American Behavioral Scientist, 36, 309-338.

Gasper, K., \& Clore, G. L.(1998).The persistent use of negative affect by anxious individuals to estimate risk. Journal of Personality and Social Psychology, 74, 1350-1363.

Gaylin, W. (1984). The rage within. New York, NY: Simon \& Schuster.

Geddes, D. \& Callister, R. (2007). Crossing the line(s): A Dual Threshold Model of anger in organizations, Academy of Management Review. 32, 721-746.

Geen, R. G. (1968). Effects of frustration, attack and prior training in aggressiveness upon aggressive behavior. Journal of Personality and Social Psychology, 9, 316-321.

Geen, R. G. (1990). Human aggression. Pacific Grove, CA: Brooks/Cole.

Giancola, P. R., \& Zeichner, A. (1995). Construct validity of a competitive reaction time paradigm. Aggressive Behavior, 21, 199-204.

Goldberg, J. H.,Lerner, J. S.,\&Tetlock, P. E.(1999). Rage and reason: The psychology of the intuitive prosecutor. European Journal of Social Psychology, 29, 781-795.

Graham, S., \& Hoehn, S. (1995). Children's understanding of aggression and withdrawal as social stigma: An attributional analysis. Child Development, 66, 1143-1161.

Green, J. G. (2012). Intermittent explosive disorder in the national comorbidity survey replication adolescent supplement intermittent explosive disorder in adolescents. 
Archives of General Psychiatry, 69, 1131-1139.

doi:10.1001/archgenpsychiatry.2012.592

Greenberg, L. S. (2002). Integrating an emotion-focused approach to treatment into psychotherapy integration. Journal of Psychotherapy Integration, 12, 154-189.

Grogger, J., 1997. Local violence and educational attainment. Journal of Human Resources, 32, $659-682$.

Gross, J. J. (2001). Emotion regulation in adulthood: timing is everything. Current Directions in Psychological Science, 10, 214-219.

Gross, J. J., John, O. P. (2003). Individual differences in two emotion regulation processes: implications for affect, relationships, and well-being. Journal of Personality and Social Psychology, 85, 348-362

Gross, J.J., \& Levenson, R.W. (1997). Hiding feelings: the acute effects of inhibiting positive and negative emotions. Journal of Abnormal Psychology, 106, 95-103.

Hanish, L., Eisenberg, N., Fabes, R., Spinrad, T., Ryan, P., \& Schmidt, S. (2004). The expression and regulation of negative emotions: Risk factors for young children's peer victimization. Development and Psychopathology, 16, 335-353.

Hauber, R. P., Rice, M. H., Howell, C. C., \& Carmon, M. (1998). Anger and blood pressure readings in children. Applied Nursing Research, 11, 2-11.

Hinde, R. A. (1985). Expression and negotiation. In G. Zivin (Ed.), The development of expressive behavior (pp. 103-116). Orlando, FL: Academic Press.

Hochschild, A. R., (1993). The managed heart: Commercialization of human feeling. University of California Press, Oakland: CA. 
Howells, K. (2004). Anger and its links to violent offending. Psychiatry, Psychology and Law, 11, 189-196.

Howells, K., \& Day, A. (2003). Readiness for anger management: Clinical and theoretical issues. Clinical Psychology Review, 23, 319-337.

Huesmann, L. R. (1988). An information-processing model for the development of aggression. Aggressive Behavior, 14,13-24.

Huesmann, L. (1998). The role of social information processing and cognitive schema in the acquisition and maintenance of habitual aggressive behavior. In R. G. Geen \& E. Donnerstein (Eds.), Human aggression: Theories, research, and implications for social policy (pp. 73-109). New York, NY: Academic Press.

Hughes, P. M. (2001). Anger. In Encyclopedia of Ethics, 2nd Ed. (Vol. I, pp. 66-70). New York, NY: Rutledge Press

Kavanagh, D. J., Andrade, J., \& May, J. (2005). Imaginary relish and exquisite torture: The elaborated intrusion theory of desire. Psychological Review, 112, 446-467.

John, O.P., \& Gross, J.J. (2004). Healthy and unhealthy emotion regulation: personality processes, individual differences, and lifespan development. Journal of personality, 72, $1301-1334$.

Joffe, R. D., Dobson, K. S., Fine, S., Marriage, K., \& Haley, G. (1990). Social problem-solving in depressed, conduct-disordered, and normal adolescents. Journal of Abnormal Child Psychology, 18, 565-575.

Jones, E. E., \& Pittman, T. S. (1982). Towards a general theory of strategic self-presentation. In J. Suls (Eds.), Psychological perspectives on the self (pp. 231-262). Hillsdale, NJ: Erlbaum. 
Josephson, W. L. (1988). Television violence and children's aggression: Testing the priming, social script, and disinhibition predictions. Journal of Personality and Social Psychology, $53,882-890$.

Kassinove, H., Sukhodolsky, D., G., Tsytsarev, S. V., \& Solovyova, S. (1997). Self-reported anger episodes in Russia and America. Journal of Social Behavioral and Personality, 12, 301-324.

Kazdin, A. E. (1995). Conduct disorders on childhood and adolescence. (2nd ed.). Thousand Oaks, CA: Sage.

Keating, C. F. (1985). Human dominance signals: The primate in us. In S. L. Ellyson \& J. F. Dovidio (Eds.), Power, dominance, and nonverbal behavior (pp. 89-108). New York, NY: Springer-Veriag.

Keltikangas-Jorvinen, L., \& Kangas, P. (1988). Problem-solving strategies in aggressive and nonaggressive children. Aggressive Behavior, 14, 255-264.

Keltner, D., \& Haidt, J. (2001). Social functions of emotions. In T. J. Mayne \& G. A. Bonanno (Eds.), Emotions: Current issues and future directions (pp. 192-213). New York: Guilford.

Kemp, S., \& Strongman, K. T. (1995). Anger theory and management: A historical analysis, The American Journal of Psychology, 108, 397-417.

Kollar, M., Groer, M., Thomas, S., \& Cunningham, J. L. (1991). Adolescent anger: A developmental study. Journal of Child and Adolescent Psychiatric and Mental Health Nursing, 4, 9-15. 
Kross, E. (2009). When self becomes other: Toward an integrative under-standing of the processes distinguishing adaptive self-reflection from rumination. Annals of the New York Academy of Sciences, 1167, 35-40.

Kross, E., Ayduk, O., \& Mischel, W. (2005). When asking “why” doesn’t hurt: Distinguishing reflective processing of negative emotions from rumination. Psychological Science, 16, $709-715$.

Kross, E., \& Ayduk, O. (2008).Facilitating adaptive emotional analysis: Short-term and longterm outcomes distinguishing distanced-analysis of negative emotions from immersedanalysis and distraction. Personality and Social Psychology Bulletin, 34, 924-938.

Kross, E., Duckworth, A., Ayduk, O., Tsukayama, E., \& Mischel, W. (2011). The Effect of selfdistancing on adaptive versus maladaptive self-reflection in children. Emotion. 11, 10321039.

Kupersmidt, J. B., \& Coie, J. D. (1990). Preadolescent peer status, aggression, and school adjustment as predictors of externalizing problems in adolescence. Child Development, $61,1350-1362$.

Labott, S. M., Martin, R. B., Eason, P. S., \& Berkey, E. Y. (1991). Social reactions to the expression of emotion. Cognition and Emotion, 5, 397-417).

Larson, R.J., \& Kasimatis, M. (1991). Day-to-day physical symptoms: Individual differences in the occurrence, duration, and emotion concomitants of minor daily illnesses. Journal of Personality, 59, 387- 423.

Lerner, J. S.,Goldberg, J. H.,\& Tetlock, P. E.(1998). Sober second thought: The effects of accountability, anger and authoritarianism on attributions of responsibility. Personality and Social Psychology Bulletin, 24, 563-574. 
Lerner, J. S., \& Keltner, D. (2000). Beyond valence: Toward a model of emotion-specific influences on judgment and choice. Cognition and Emotion, 14, 473-493.

Lerner, J. S., \& Keltner, D. (2001). Fear, anger, and risk. Journal of Personality and Social Psychology, 81, 146-159. doi:10.1037/0022-3514.81.1.146

Liberman, N., Sagristano, M., \& Trope, Y. (2002). The effect of temporal distance on level of mental construal. Journal of Experimental Social Psychology, 38, 523-534.

Litvak, P. M., Lerner, J. S., Tieden, L. Z., \& Shonk, K. (2010). Fuel in the fire: How anger impacts judgment and decision-making. International handbook of anger. New York, NY: Springer.

Lochman, J. E., \& Dodge, K. A. (1994). Social-cognitive processes of severely violent, moderately aggressive, and nonaggressive boys. Journal of Consulting and Clinical Psychology, 62, 366-374.

Lyubomirsky, S., \& Nolen-Hoeksema, S. (1995). Effects of self-focused rumination on negative thinking and interpersonal problem solving. Journal of Personality and Social Psychology, 69, 176-190.

Mahon, N. E., Yarcheski, A., \& Yarcheski, T. J. (2000). Positive and negative outcomes of anger in early adolescents. Research in Nursing \& Health, 23, 17-24.

Martin, L. L., \& Tesser, A. (1989). Toward a motivational and structural theory of ruminative thought. In J. S. Uleman \& J. A. Bargh (Eds.), Unintended thought (pp. 306-326). New York: Guilford Press. 
Matthys, W., Cuperus, J. M., \& Van Engeland, H. (1999). Deficient social problem-solving in boys with $\mathrm{ODD} / \mathrm{CD}$, with ADHD, and with both disorders. Journal of the American Academy of Child and Adolescent Psychiatry, 38, 311-321.

Mauss, I. B., Cook, C. L., Cheng, J. Y. J., \& Gross, J. J. (2007). Individual differences in cognitive reappraisal: Experiential and physiological responses to an anger provocation. International Journal of Psychophysiology, 66, 116-124.

Mazerolle, P., Piquero, A., (1997). Violent responses to strain: an examination of conditioning influences. Violence and Victims, 12, 323-343.

Mazerolle, P., Burton Jr., V. S., Cullen, F. T., Evans, T. D., Payne, G. L., (2000). Strain, anger, and delinquent adaptations: Specifying general strain theory. Journal of Criminal Justice, $28,89-101$.

Mischkowski, D., Kross, E., \& Bushman, B. J. (2012). Flies on the wall are less aggressive: Self-distancing "in the heat of the moment" reduces aggressive thoughts, angry feelings and aggressive behavior. Journal of Experimental Social Psychology, 48, 1187-1191.

Miller, N., Pedersen, W. C., Earleywine, M., \& Pollock, V. E. (2003). A theoretical model of triggered displaced aggression. Personality and Social Psychology Review, 7, 75-97

Moffitt, T. E. (1993). Adolescence-limited and life-course-persistent antisocial behavior: A developmental taxonomy. Psychology Review, 100, 674-701.

Morris, M. W., \& Keltner, D. (2000). How emotions work: The social functions of emotional expression in negotiations. In B. M. Staw \& R. I. Sutton (Eds.), Research in organizational behavior (Vol. 11, pp. 1-50). Amsterdam, the Netherlands: JAI Press. 
Morrow, J., \& Nolen-Hoeksema, S. (1990). Effects of responses to depression on the remediation of depressive affect. Journal of Personality and Social Psychology, 58, 519-527.

Moss, H. B., \& Kirisci, L. (1995). Aggressivity in adolescent alcohol abusers: Relationship with conduct disorder.Alcoholism. Clinical and Experimental Research, 19, 642-646.

Muraven, M., Tice, D.M., Baumeister, R.F., 1998. Self-control as a limited resource: regulatory depletion patterns. Journal of Personality and Social Psychology 74, 774-789.

Nichols, T. R., Mahaded, M., Bryant, K., \& Botvin, G. J. (2008). Examining anger as a predictor of drug use among multiethnic middle school students. Journal of School Health, 78, 480-486.

Nolen-Hoeksema, S. (1991). Responses to depression and their effects on the duration of depressive episodes. Journal of Abnormal Psychology, 100, 569-582.

Nolen-Hoeksema, S. (2000). The role of rumination in depressive disorders and mixed anxiety/depressive symptoms. Journal of Abnormal Psychology, 109, 504-511.

Nolen-Hoeksema, S., Wisco, B., \& Lyubomirsky, S. (2008). Rethinking rumination. Perspectives on Psychological Science, 3, 400-424.

Novaco, R. (1975). Anger control: The development and evaluation of an experimental treatment. Lexington, MA: Heath.

Novaco, R.W. (1976). The functions and regulations of the arousal of anger. American Journal of Psychiatry, 133, $1124-1127$.

Novaco, R. W. (2000). Anger. Encyclopedia of Psychology (Vol. 1, pp. 170-174). New York, NY: Oxford University Press, 2000 
O’Connor, B. P. (1995). Identity development and perceived parental behaviour as sources of adolescent egocentrism. Journal of Youth and Adolescence, 24, 205-227.

Ochsner, K. N., Ray, R. R., Cooper, J. C., Robertson, E. R., Chopra, S., Gabrieli, J. D. E., Gross, J. J., (2004). For better or for worse: neural systems supporting the cognitive down- and up-regulation of negative emotion. Neuroimage, 23, 483-499.

Parker, D., Lajunen, T., Summala, H. (2002). Anger and aggression among drivers in three European countries. Accident Analysis and Prevention, 34, 229-235.

Patterson, G. R., Forgatch, M. S., Yoerger, K. L., \& Stoolmiller, M. (1998).V ariables that initiate and maintain an early onset trajectory for juvenile offending. Developmental and Psychopathology, 10, 531-547.

Pennebaker, J. W. (1997). Writing about emotional experiences as a therapeutic process. Psychological Science, 8, 162-166.

Pennebaker, J. W., \& Graybeal, A. (2001). Patterns of natural language use: Disclosure, personality, and social integration. Current Directions in Psychological Science, 10, 9093.

Piaget, J. (1929). The child's conception of the world. London: Kegan Paul, Trench \& Trubner.

Piaget, J., \& Inhelder, B. (1956). The child's conception of space. London: Routledge \& Kegan Paul.

Pope, A. W., \& Bierman, K. L. (1999). Predicting adolescent peer problems and antisocial activities: The relative roles of aggression and dysregulation. Developmental Psychology, $35,335-346$.

Polivy, J. (1998). The effects of behavioral inhibition: integrating internal cues, cognition, behavior, and affect. Psychological inquiry, 9, 181-204. 
Rachman, S. (1981).Emotional processing. Behaviour Research and Therapy, 18, 51-60.

Raghunathan, R., \& Pham, M. T. (1999). All negative moods are not equal: Motivational influences of anxiety and sadness on decision making. Organizational Behavior and Human Decision Processes,79, 56-77.

Raine, A. (2008). From genes to brain to antisocial behaviour. Current directions in psychological science, 17, 323-328.

Richard, B. A., \& Dodge, K. A. (1982). Social maladjustment and problem solving in schoolaged children. Journal of Consulting and Clinical Psychology, 50, 226-233.

Rozin, P., Millman, L., \& Nemeroff, C. (1986). Operation of the laws of sympathetic magic in disgust and other domains. Journal of Personality and Social Psychology, 50, 703-712.

Rule, B. G., \& Percival, E. (1971).The effects of frustration and attack on physical aggression. Journal of experimental research in personality, 5, 111-118.

Rusting, C. L., \& Nolen-Hoeksema, S. (1998). Regulating responses to anger: Effects of rumination and distraction on angry mood. Journal of Personality and Social Psychology, $74,790-803$.

Rutledge, T., \& Hogan, B. E. (2002). A quantitative review of prospective evidence linking psychological factors with hypertension development. Psychosomatic Medicine, 64, 758766.

Scherer, K. R., \& Wallbott, H. G. (1994). Evidence for universality and cultural variation of differential emotion response patterning. Journal of Personality and Social Psychology, $66,310-328$

Schumacher, J. A., Feldbau-Kohn, S., Slep, A. M. S., \& Hayman, R. E. (2001). Risk factors for male-to-female partner physical abuse. Aggression and Violent Behavior, 6, 281-352. 
Schwartz, P. D., Maynard, A. M., \& Uzelac, S. M. (2008). Adolescent egocentrism: A contemporary view. Adolescence, 43, 441-448.

Siever, L. J. (2008). Neurobiology of aggression and violence. American Journal of Psychiatry, $165,429-442$.

Silverman, L. H. (1983). The subliminal psychodynamic activation method: Overview and comprehensive listing of studies. In J. Mashing (Ed.). Empirical studies of psychoanalytic theories (Vol. 1; pp. 69-100). Hillsdale, NJ: Erlbaum.

Singer, M. I., \& Flannery, D. J. (2000). The relationship between children's threats of violence and violent behaviors. Archives of Pediatric and Adolescent Medicine, 154, 785-790.

Slaby, R. G., \& Guerra, N. G. (1988). Cognitive mediators of aggression in adolescent offenders. Developmental Psychology, 24, 580-588.

Spielberger, C. D. (1996). State-Trait Anger Expression Inventory: Professional manual. Odessa, FL: Psychological Assessment Resources, Inc.

Spielberger, C. D., Jacobs, G., Russell, S., \& Crane, R. S. (1983). Assessment of anger: The State-Trait Anger Scale. In J. N. Butcher \& C. D. Spielberger (Eds.), Advances in personality assessment. (Vol. 3, pp. 112-134). Hillsdale, NJ: Lawrence Erlbaum Associates.

Stanton, A. L., Danoff-Burg, S., Cameron, C. L., Bishop, M., Collins, C. A., Kirk, S. B., Sworowski, L. A., \& Twillman, R. (2000). Emotionally expressive coping predicts psychological and physical adjustment to breast cancer. Journal of Consulting and Clinical Psychology, 68, 875-882. 
Stearns, C. Z., \& Stearns, P. N. (1986). Anger: The struggle for emotional control in America's history. Chicago, IL: University of Chicago Press.

Stein, D., Apter, A., Ratzoni, G., Har-Even, D., \& Avidan, G. (1998). Association between multiple suicide attempts and negative affects in adolescents. Journal of the American Academy of Child and Adolescent Psychiatry, 37, 488-494.

Steinberg, L. (2005). Psychological control: Style or substance? New Directions for Child and Adolescent Development, 2005, 71-78. doi:10.1002/cd.129

Steinberg, M. D., \& Dodge, K. A. (1983). Attributional bias in aggressive adolescent boys and girls. Journal of Social and Clinical Psychology, 1, 312-321.

Sutton, R. I. (1991) Maintaining norms about expressed emotions: The case of bill collectors, Administrative Science Quarterly, 36, 245-268.

Sukhodolsky, D. G., Golub, A., Cromwell, E.N. (2001). Development and validation of the anger rumination scale. Personality and individual difference, 31, 689-700.

Tavris, C. (1982). Anger: The misunderstood emotion. New York, NY: Simon \& Schuster.

Taylor, S. P. (1967). Aggressive behavior and physiological arousal as a function of provocation and the tendency to inhibit aggression. Journal of Personality, 35, 297-310.

Teasdale, J. D. (1988). Cognitive vulnerability to persistent depression. Cognition and Emotion, 2, 247-274.

Tennant, C., \& McLean, L. (2001). The impact of emotions on coronary heart disease risk. Journal of Cardiovascular Risk, 8, 175-83.

Thompson, R. A. (1994). Emotion regulation: A theme in search of definition. Monographs of the Society for Research in Child Development, 59, 2-3. doi:10.2307/1166137 
Tiedens, L. Z. (2000). Powerful emotions: The vicious cycle of social status positions and emotions. In N. M. Ashkanasy, C. E. J. Ha rtel, \& W. J. Zerbe (Eds.), Emotions in the workplace: Research, theory and practice (pp. 71-81). Westport, CT: Quorum.

Tiedens , L. Z. (2001). Anger and advancement versus sadness and subjugation: the effect of negative emotion expressions on social status conferral, Journal of Personality \& Social Psychology, 90, 86-94.

Tobin, T., \& Sprague, J. (2000). Alternate educational strategies: Reducing violence in school and community. Journal of Emotional and Behavioral Disorders, 8, 177-186.

Tyson, P. D. (1998). Physiological arousal, reactive aggression, and the induction of an incompatible relaxation response. Aggression and violent behavior, 3, 143-158.

Van Kleef, G. A., De Dreu, C. K., \& Manstead, A. S. (2004). The interpersonal effects of anger and happiness in negotiations, Journal of Personality and Social Psychology, 86, 57-76.

Vartanian, L. R. (2001). Adolescents' reactions to hypothetical peer group conversations: Evidence for an imaginary audience. Adolescence, 36, 347-380.

Watson, D., Clark, L. A., \& Tellegen, A. (1998). Development and validation of brief measures of positive and negative affect: The PANAS scales. Journal of Personality and Social Psychology, 54, 1063-1070.

Webster-Stratton, C., \& Lindsay, D. W. (1999). Social competence and conduct problems in young children: Issues in assessment. Journal of Clinical Child Psychology, 28, 25-43.

Weiner, B. (1986). Attribution, emotion, and action. In R. M. Sorrentino \& E. T. Higgins (Eds.), Handbook of motivation and cognition: Foundations of social behavior (pp. 281-312). New York, NY: Guilford. 
Wilde, J. (1996). Treating anger, anxiety, and depression in children and adolescents: A cognitive-behavioral perspective. Washington, DC: Accelerated Development.

Wilson, T., \& Gilbert, D. (2008).Explaining away: A model of affective adaptation. Perspectives on Psychological Science, 3, 370-386.

Woolfolk, A.E. (2010). Educational psychology. London, England: Pearson.

Yarcheski, A., Mahon, N. E., \& Yarcheski, T. J. (2002). Anger in early adolescent boys and girls with health manifestations. Nursing Research, 51, 229-236.

Zillmann, D. (1979). Hostility and aggression. Hillsdale, NJ: Lawrence Erlbaum. 


\section{Appendix A Site Permission Letter}

September 17, 2013

Dear Principal Louis F. DeLoreto,

I am writing to request permission to conduct psychological experiments on students in Edwin O. Smith High School for my doctoral dissertation entitled "Self-Distancing to Reduce Anger in High School Students". Self-distancing has been found to lead to lower aggressive thoughts, angry feelings, displaying less aggressive behaviors, improved interpersonal interactions, long-term emotional well-being, and physiological health. While previous literature on self-distancing suggest that it has promising potential as a quick and effective intervention for anger in young adult and child populations, no research, as of yet, has been conducted with adolescents, even though it is a population particularly prone to the devastatingly negative consequences of anger and aggression.

For the purpose of this study, I will need to recruit from 66 to up to 220 students between the ages of 14 to 17 who will meet selection criteria: 1) Participants should not have auditory, visual, or reading difficulties that will interfere with understanding directions or completing procedures; 2) participants should not be prone to severe anger, aggression, frustration, depression or anxiety that may interfere with study procedures or later academic instruction. All students will be sent home a recruitment flyer outlining basic study procedures, inclusion/exclusion criteria, benefits/compensation, and a request for parent/guardian contact information if they interested in having their children participate. Potential participants will be asked to turn this form into the main office for the experimenter to collect. Parents will then be contacted individually to be informed about the specific details of the study's purpose and procedures, including procedures in which the child will experience incomplete disclosure of study purpose, hypothesis, and measures, as well as a description of risks and benefits of participation. If parents indicate interest in participation after the phone call, they will be mailed Parent Permission forms to sign and return to experimenters using an enclosed return envelope.

Upon receiving signed Parent Permission forms, I would like a team of reviewers, made up of the assistant principal, school psychologist, and grade level counselors to meet as a team to review the list for students with IEPs or 504 plans for visual and auditory disorders or disabilities and severe emotional disturbance, including students with known diagnoses of moderate to severe anxiety or depression. For students identified with a reading disability, reading should be at least at a $7^{\text {th }}$ grade level. Based on their knowledge of the study procedures, exclusion criteria, and potentials risks, reviewers may propose that students without IEPS or 504 plans be excluded. These individuals will be excluded if the team of reviewers comes to a group consensus that including such individuals would pose a greater risk to the student or school than any potential benefit of participation in the study.

In this study I propose to employ an experimental design to examine the efficacy of selfdistancing as an intervention to reduce anger in a sample of high school students. More specifically, I am comparing a self-distancing treatment group to a control group to see if the 
treatment group will experience less implicit aggression, anger, and less negative affect than participants in the control group.

Prior to initiation of study procedures, participants will be randomly assigned to either treatment or control group. On the morning of the study, participants will receive a message stating that they are have been selected for participation and are report to either a designated waiting room or experiment room together with other participants in the same treatment group when summoned by school officials. Experimentation sessions are expected to last approximately 10 to 15 minutes per group, with the total time for the control group being up to approximately 25-30 minutes due to the time they may wait for the other group to finish the experiment. Participants will receive a Child Assent Form that states that they are participating in a study examining the adolescent anger and that they will be asked to recall a past experience in which they felt anger and hostility towards someone.

In order to prevent participants from trying to guess the study hypothesis and provide biased responses, incomplete disclosure is necessary. The assent form will also outline basic procedures and notes that a detailed explanation of the study's purpose and procedures will be presented to them at the end of the study so as not to bias responses. The assent form will also reiterate inclusion/exclusion criteria noted in the parent permission form, recruitment flyer, and noted in the parent phone conversation. Participants will also be informed of their rights to privacy of data collected and the right to terminate participation at any time. Participants will be compensated for their participation with a pass for a free movie at the Mansfield Movieplex and entry into a raffle for an iPad Mini. Participants will also receive the educational benefit of participating in an actual social science experiment, including an explanation of the intervention for future personal application.

Participants will be told that the first task involves recalling a time when you were angry at someone. Through the audio device, participants will be instructed to close their eyes and "Recall an interpersonal experience in which you felt overwhelming anger and hostility." After a minute, participants will be given additional instructions via audio device. Participants assigned to the control group will be told to "Go back to the time and place of the experience you just recalled and see the scene in your imagination. Now see the situation unfold through your own eyes as if it were happening to you all over again. Replay the event as it unfolds in your imagination through your own eyes." Participants in the self-distancing group will be told, "Now close your eyes. Go back to the time and place of the experience you just recalled and see the scene in your imagination. Now take a few steps back. Move away from the situation to a point where you can now watch the even unfold from a distance and see yourself in the event. As you do this, focus on what has now become the distant you. Now watch the situation unfold as if it were happening to the distant you all over again. Replay the event as it unfolds in your imagination as you observe your distant self." After 45 seconds, participants will be asked to complete measures of implicit aggression, anger, and negative affect. The implicit anger measure will be list of incomplete words with seven words embedded that can be completed with either aggressive or neutral words (e.g. M_D). The measure of implicit aggression, anger, and negative affect will consist of items rating anger, irritability, hostility and annoyance that are embedded among filler items and the negative affect subscale of the Positive Affect Negative Affect Scale. 
To conclude the trial, the control group will also listen to the self-distancing script. To conclude the study all participants will receive a letter of debriefing. The debriefing will include 1) an expression of appreciation for participation in the study, 2) an explanation of the true purpose of the study, 3) an explanation of the procedures, 4) an explanation for why participants were not fully informed about the purpose of the study, treatments, and measures, 5) the potential benefits of this study on the development of the field of anger research and psychoeducational services, as well as a suggestion for the personal application of self-distancing for dealing with anger, and 6) the contact information of the primary investigator in case there are any questions or concerns. An experimenter will verbally highlight these six major areas and welcome questions. Participants will then be thanked for their participation, will receive compensation (movie pass), and will be informed of the timeframe in which they can expect the results of the iPad Mini raffle to be announced. Participants will also be reminded not to discuss study procedures with peers until all groups have completed the experiment procedures. Furthermore, counselors are available if they still feel angry, upset or agitated..

I would like to ask for permission to recruit participants from your student population, administrate study procedures on-site, and debrief your students upon completion of the study. I would also like to request support in distributing recruitment flyers, collecting recruitment forms and parent permission forms, screening students based on exclusion criteria, locating students at the time of experimental trials, and offering mental health support services to participants in the rare instance a participant has an adverse reaction to the study procedures.

I have enclosed a copy of my IRB-1 Protocol Application for the Involvement of Human Participants in Research, with all relevant forms for this study included in the appendices. A copy of the approved IRB-1 Protocol Application for the Involvement of Human Participants in Research will also be provided upon approval. Should you have any questions or concerns regarding this letter or my research, please contact me at the email address above or contact Dr. Thomas J. Kehle, advisor, at thomas.kehle@uconn.edu.

If you consent to allowing me to conduct my experiment with the procedures outlined above, please sign your name below.

Sincerely,

Koichi Yoshikawa

Principal Name and Date

Principal Signature 


\title{
University of Connecticut
}

\section{Volunteers Wanted for Research Study}

\author{
Anger in High School Students
}

Volunteers are wanted to participate in research on anger in high school students. Volunteers will be asked to volunteer approximately 10 minutes during school to participate in experimental procedures, including a short reflection taskandsome questionnaires about emotions.

Volunteers should be high school students enrolled at E.O. Smith High School between the ages of 14 to 17. Participants should not have reading, listening, or reading difficulties that would interfere with understanding directions or completing procedures. Because one of the tasks asks you to think about a time you were angry, participants should not be prone to severe anger, aggression, frustration, depression, or anxiety that may interfere with completion of study procedures or create difficulties when returning to classroom instruction.

Participants will have the learning experience of participating in psychology research, including a full explanation of research purpose and procedures and practical applications of the research for daily life upon completion of the study.

Participants will receive a gift pass to see one movie at the Mansfield Movieplex and a chance to win an iPad Mini.

If you are interested in participating, have a parent/guardian fill out the bottom section of this page and turn it into the main office. A researcher will contact your parent/guardian to answer any questions and explain the procedures in detail. You may also call Koichi Yoshikawa, doctoral candidate in school psychology at (858)371-1162.

This research is conducted under the direction of Thomas J. Kehle, Department of Educational Psychology.

Parent/guardian

Signature

Child's name Child's grade

Parent/guardian phone number Best time to call 


\section{Appendix C \\ Parental Recruitment/Parent Information Phone Call Script}

The reason for this call:

Good morning/afternoon/evening. My name is Koichi Yoshikawa and I'm calling in regards to the research recruitment flyer you signed from EO Smith.

The reason I'm calling you directly is because there are a few elements of the study that have to be discussed with the parent/guardians of participants without their children knowing. If your child were to know the actual purpose of this study, they would not be able to give natural responses and it would contaminate the data.

I want share a little about the procedures your child would experience.

\section{The actual purpose:}

The real purpose of this study is to test the effect of "self-distancing", which is a new type of very quick anger intervention. It has been tested with adults, young college students, and children, but not with adolescents, who may arguably benefit the most from it.

\section{The procedure:}

So on the day of experimentation, your child and other participants will be escorted to a room in EO Smith and given a form that gives a simplified outline of the experimental procedures). They will be informed that they are not being told details of the purpose or procedures so that they can respond naturally. They are also told that the one task involves remembering a time they were very angry, that they have the right to privacy and to quit at any time for any reason.

For the first task, your child will be told though an audio device, to close their eyes and "Recall an interpersonal experience in which you felt overwhelming anger and hostility."

Your child will have been randomly placed into the self-distancing group or the control group If your child is assigned to the control group, they will be told to "Go back to the time and place of the experience you just recalled and see the scene in your imagination. Now see the situation unfold through your own eyes as if it were happening to you all over again. Replay the event as it unfolds in your imagination through your own eyes." If your child is in the self-distancing group, they will be told, "Now close your eyes. Go back to the time and place of the experience you just recalled and see the scene in your imagination. Now take a few steps back. Move away from the situation to a point where you can now watch the even unfold from a distance and see yourself in the event. As you do this, focus on what has now become the distant you. Now watch the situation unfold as if it were happening to the distant you all over again. Replay the event as it unfolds in your imagination as you observe your distant self." After analyzing his/her emotions for 45 seconds, your child will fill out two questionnaires. One of them is a word completion task which can be completed to create neutral words or aggressive words. For example, M_D can be completed MUD or MAD. The other questionnaires ask them to rate emotions, like "How do you feel?" We will only be interested in the emotions that relate to anger, irritability, hostility, and annoyance and general negative affect/feeling. 
To conclude the study, your child will receive a letter of debriefing that will explain the true purpose of the study, study procedures, a discussion of why participants were not fully informed of the purpose and procedures, the benefits of this study, and the contact information of experimenters in case there are any questions or concerns. Your child will then be thanked, given a movie pass and entered into the raffle. You child will also be told not to share what happened in the experiment

Risks:

Your child may experience discomfort recalling an experience in which they felt angry. Because of this risk, we ask that you not volunteer your child if you feel your child is prone to depression, anxiety, aggression or anger. In case your child may still feel upset after the study, counselors and psychologists will be available.

\section{What I would like from you if you are interested:}

At this point I would like to ask that you please not discuss the purpose or procedures of the study to your child or other students and parents at your child's school. You may tell your child that it will be about the experience of anger.

If you are still interested in your child participating I can send you a Parent Permission Form that will explain everything I've mentioned in detail. It will come through the school in a sealed envelope with another self-addressed stamped envelope. Please note that even if you agree to have your child participate, the school will make the final decision about whether or not your child can participate.

Would you like to have your child participate?

Thank you very much. If you have any questions, you can feel free to call me at this number. My contact information and contact information of my advisor will be included in the Parent Permission Form as well.

(Conclude Call) 


\title{
Parental Permission Form for Participation in a Research Study
}

\section{Wniversity of Connecticut}

\author{
Principal Investigator: Thomas J. Kehle, PhD \\ Student Researcher: Koichi Yoshikawa, MA \\ Study Title: Self-distancing to reduce anger in a high school population
}

\begin{abstract}
Introduction
Your child is invited to participate in a research study to examine the effect of self-distancing as an intervention for promoting healthy reflection to unresolved anger inducing events in high school students. Your child is being asked to participate because he/she is a high school student between the ages of 14-17 years old.
\end{abstract}

This permission form will give you the information you will need to understand why this study is being done and why your child is being invited to participate. It will also describe what your child will be asked to do to participate and any known risks, inconveniences or discomforts that your child may have while participating. We encourage you to take some time to think this over and to discuss it with your child, other family members, friends and, if applicable, your child's doctor. We also encourage you to ask questions now and at any time. If you decide to participate, you will be asked to sign this form, your child may be asked to sign the form and it will be a record of your permission to allow your child to participate. You will be given a copy of this form.

\section{Why is this study being done?}

When an unpleasant event occurs, people often reflect on the situation in a way that fuels aggressive thoughts and angry feelings. Self-distancing is a quick and effective intervention that has been found to lead to lower aggressive thoughts, angry feelings, displaying less aggressive behaviors, improved interpersonal interactions, long-term emotional well-being, and physiological health. When self-distancing, people see themselves from afar and look at the broader context of the situation and not as a victim. Despite its promising potential as an intervention for anger in young adult and child populations, no research, as of yet, has been conducted with adolescents, even though it is a population particularly prone to the devastatingly negative consequences of anger and aggression.

\section{What are the study procedures? What will my child be asked to do?}

In order to participate in this study, each individual must meet certain criteria. First, participants must be of 14 to 17 years of age. Second, individuals must possess visual, auditory, and reading abilities sufficient for understanding and complying with study procedures. Third, individuals must not have a history of severe anger, aggression, frustration or anxiety that may be aggravated and lead to the disruption of study procedures or later academic instruction. 
The study will be conducted one day in the 2013-2014 academic year on the campus of Edwin O. Smith High School. If you give permission for your child to take part in this study, your child will be randomly assigned to one of two treatment groups using a random number generator. One group will be the self-immersion group that will be asked to reflect on an anger inducing experience as it were happening again, while the other group will be part of the self-distancing group that is asked to relive an anger inducing experience from an outside observer's perspective. On the day of experimentation, your child will be asked to report to either a waiting room or directly to the room in which experimental procedures will be conducted together with other students in his/her treatment group.

Your child will first be provided a Child Assent Form. This form will state that the purpose of the study is to examine anger in adolescents. Your child will be informed that in order to ensure that they give natural responses, they will not be informed of the full purpose of the study or be given a detailed explanation of procedures until the completion of study procedures. The assent form will also indicate participant rights, notably, the right to terminate participation at any time and to the privacy of data collected.

All participants will be told that the first task involves recalling a time when you were angry at someone. Through the audio device, participants will be instructed to close their eyes and "Recall an interpersonal experience in which you felt overwhelming anger and hostility."

After a minute, participants will be given additional instructions via audio device. Participants assigned to the control group will be told to "Go back to the time and place of the experience you just recalled and see the scene in your imagination. Now see the situation unfold through your own eyes as if it were happening to you all over again. Replay the event as it unfolds in your imagination through your own eyes." Participants in the self-distancing group will be told, "Now close your eyes. Go back to the time and place of the experience you just recalled and see the scene in your imagination. Now take a few steps back. Move away from the situation to a point where you can now watch the even unfold from a distance and see yourself in the event. As you do this, focus on what has now become the distant you. Now watch the situation unfold as if it were happening to the distant you all over again. Replay the event as it unfolds in your imagination as you observe your distant self." Next, all participants will analyze their emotions for 45 seconds, while maintaining their initial perspective.

After 45 seconds, participants will be asked to complete measures of implicit aggression, anger, and negative affect/feelings. The implicit aggression measure will be a list of incomplete words with seven words that can be completed with either aggressive or neutral words (e.g. M_D). Implicit aggression, anger and negative affect will be measured directly with a 1 to 5 scale.

To conclude the trial, participants in the control group will listen to the self-distancing script and all participants will receive a letter of debriefing which will include an expression of gratitude for participation, an explanation of the true purpose of the study, an explanation of study procedures, a discussion of why participants were not fully informed of the purpose and procedures, the benefits of this study for the field and for personal application, and the contact information of experimenters in case there are any questions or concerns. All major elements of the letter will be reviewed by an experimenter and questions welcomed. Participants will then be 
thanked for their participation, will receive compensation, and will be informed of the timeframe in which they can expect the results of the iPad Mini raffle to be announced. They will also be informed that if they feel angry, upset or agitated after the experiment, they may request to see a counselor.

\section{What are the risks or inconveniences of the study?}

One inconvenience may be the time demand of about 10 to 25 minutes it takes to complete the experimental procedures. Possible risks include emotional discomfort or stress due to agitation or frustration associated with the timed anagram task. Participants are intended to experience mild frustration and agitation from the provocations of the prerecorded voice. They may also experience frustration trying to answer questions under a time limit. In the instance your child or the experimenter no longer wishes to proceed with procedures, the trial will be terminated. School mental health professional will also be available if your child is distressed.

\section{What are the benefits of the study?}

Your child may enjoy the educational experience associated with participation in a research study. However, there may not be a direct benefit of the study intervention on your child. Nevertheless, at the end of the study, all participants will be given a letter of debriefing that will explain the actual purpose of the study, study procedures, and how to apply self-distancing in their personal lives. If the intervention is found to be effective, this knowledge may benefit your child's psychological well-being and functioning in multiple ways: Self-distancing has been found to lead to lower aggressive thoughts, angry feelings, displaying less aggressive behaviors, improved interpersonal interactions, long-term emotional well-being, and physiological health. The findings may also have important implications for education and for mental health professionals working with adolescent populations.

\section{Will my child receive payment for participation? Are there costs to participate?}

There are no costs to you and your child for participating in this study beyond an estimated 10 to 30 minutes for experimental procedures. Participants will be paid to participate in this study with a movie pass for a local movie theater and participation in a raffle for an iPad Mini upon completion of experimental procedures. The movie pass was selected as compensation because of the potential entertainment and social value of movie theaters for adolescents. The iPad Mini was selected as compensation due to its multiple potential educational uses and its popularity amongst adolescents. Raffle winners will be contacted at school after the completion of the study.

\section{How will my child's information be protected?}

Information that is collected from your child before or during the study will be kept confidential. All forms and data will be locked in an office at the University of Connecticut 
and only study experimenters will have access to it, unless otherwise required by law. All data will be maintained in this manner for a period of up to three years, after which point all personally identifiable information that could link your child to their data will be destroyed.

Your child will be assigned a unique identification code, and the file that links your child's name to this code will be kept with all other files in a locked office at the university. This code will be used instead of your child's name on all questionnaires and electronic data. All electronic data will include only non-personally identifiable information. At the conclusion of this study, the researchers may publish their findings. Information will be presented in summary format, and you will not be identified in any publications or presentations.

We will do our best to protect the confidentiality of the information we gather from your child but we cannot guarantee $100 \%$ confidentiality. Data that we collect from your child may be shared with other researchers in the future, but only after your child's name and all identifying information have been removed. If you decide to leave the study at any point, all data that has been collected up to the point of your child's withdrawal will be kept and may be used in analyses and publications.

You should also know that the UConn Institutional Review Board (IRB) and the Office of Research Compliance may inspect study records as part of its auditing program, but these reviews will only focus on the researchers and not on your responses or involvement. The IRB is a group of people who review research studies to protect the rights and welfare of research participants.

\section{Can my child stop being in the study and what are my and my child's rights?}

Your child does not have to be in this study if you do not want him/her to participate. If you give permission for your child to be in the study, but later change your mind, you may withdraw your child at any time. There are no penalties or consequences of any kind if you decide that you do not want your child to participate.

You will be notified of all significant new findings during the course of the study that may affect your willingness to allow your child to continue. Your child does not have to answer any question that he/she does not want to answer. Your child may also withdraw from the study at any time without penalty. If your child participates in this study the right to withdraw will be explained to your child prior to the initiation of any experimental procedures. Your child may also be withdrawn from the study if his/her behavior is disruptive, if he/she cannot adhere to procedures, or has an adverse reaction to any procedures.

\section{Whom do I contact if I have questions about the study?}

Take as long as you like before you make a decision. We will be happy to answer any question you have about this study. If you have further questions about this study or if you have a research- 
related problem, you may contact the principal investigator, (Thomas J. Kehle at 860-486-0166) or the student researcher (Koichi Yoshikawa 858-371-1162). If you have any questions concerning your child's rights as a research participant, you may contact the University of Connecticut Institutional Review Board (IRB) at 860-486-8802.

\section{Documentation of Permission:}

I have read this form and decided that I will give permission for my child to participate in the study described above. Its general purposes, the particulars of my child's involvement and possible risks and inconveniences have been explained to my satisfaction. I understand that I can withdraw my child at any time. I understand that in order to prevent potential contamination of study objectives, deception will be used on my child and some particulars of the experiment will be explained to my child upon the conclusion of the study. My signature also indicates that I have received a copy of this parental permission form. Please return this form to the child's homeroom teacher by _____ 2014 .

$\overline{\text { Child Signature: }} \quad \overline{\text { Print Name: }} \overline{\text { Date: }}$

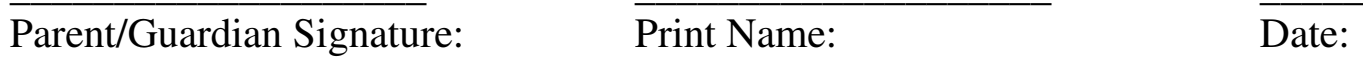

Relationship to Child (e.g. mother, father, guardian):

Signature of Person

Print Name:

Date:

Obtaining Consent 


\title{
Assent Form for Participation in a Research Study University of Connecticut
}

\author{
Principal Investigator:Thomas J. Kehle, $\mathrm{PhD}$ \\ Student Researcher:Koichi Yoshikawa \\ Study Title:Anger in high school students
}

Your parents have talked to you about being in a research study on anger in adolescents. In order to allow you to respond naturally to the tasks in this experiment, the purpose and a detailed explanation of the procedures will not be offered until after the study procedures are completed.

If you decide to be in the study you will do these things:

1. You will be asked to recall a time when you were angry at someone.

2. You will be asked to complete some questionnaires.

Altogether the procedures should take about 10 minutes. You may experience some discomfort while reflecting on your anger experiences. If you experience a lot of stress or feel upset during the study, you may quit at any time and a counselor or school psychologist will be available to talk to you.

NOTE: If you feel you are easily frustrated, upset, made very mad or very sad, please do not participate. Also, please do not participate if you have serious vision, hearing, or reading problems that will keep you from following directions.

No information about you will be shared with anyone who is not working on this study. You can ask questions about this study at any time; however, a more detailed explanation of the study will be given to you at the end of the study.

You can decide not to be in this study. You can also decide to be taken out of the study at any time or not answer particular questions. If you decide not to continue at any point, you will not be punished or penalized and the experimenters and the school will not be angry with you.

This information sheet is yours to keep.

Participant Signature:

Print Name:

Date:

Signature of Person

Print Name:

Date:

Obtaining Assent 
Appendix F

Word Completion Task for Implicit Aggression

Word Completion (ANSWER MASTER SHEET)

Directions: Now that you have analyzed your emotions, complete the 21 words below.

\begin{tabular}{|c|c|}
\hline 1. INS ULT & 12. $\mathrm{M}_{-} \mathrm{TCH}$ \\
\hline 2. $\mathrm{P}_{--\mathrm{NE}}$ & 13. $\mathrm{H} \mathrm{I} \mathrm{T}$ \\
\hline HA TE & 14. $\mathrm{V}-\mathrm{SION}$ \\
\hline $\mathrm{FL}_{--\mathrm{T}}$ & 15. $\mathrm{C}_{-} \mathrm{NTR}_{-} \mathrm{L}$ \\
\hline M A D & 16. $\mathrm{S}_{-} \mathrm{D}_{-}$ \\
\hline $\mathrm{P}-\mathrm{CK}$ & 17. $\mathrm{COO}_{-}$ \\
\hline KI LL or CK & 18. $\mathrm{D}_{--} \mathrm{R}$ \\
\hline $\mathrm{A}_{-} \mathrm{T}$ & 19. $\mathrm{FR}_{-} \mathrm{T}$ \\
\hline ANG ER & 20. $\mathrm{SH}_{-} \mathrm{RE}$ \\
\hline 10. $\mathrm{W}_{-} \mathrm{N}$ & 21. $\mathrm{W}_{-}$TER \\
\hline 11. R AGE & \\
\hline
\end{tabular}




\section{Word Completion}

Directions: Now that you have analyzed your emotions, complete the 21 words below.

\begin{tabular}{|c|c|}
\hline 1. $\mathrm{INS}_{-}-$ & 12. $\mathrm{M}_{-} \mathrm{TCH}$ \\
\hline 2. $\mathrm{P}_{-}-\mathrm{NE}$ & 13. $\mathrm{H}_{-} \mathrm{T}$ \\
\hline 3. $\mathrm{HA}_{-}$ & 14. $\mathrm{V}_{-} \mathrm{SION}$ \\
\hline 4. $\mathrm{FL}_{-} \mathrm{T}$ & 15. $\mathrm{C}_{-} \mathrm{NTR}_{-} \mathrm{L}$ \\
\hline 5. $\mathrm{M}_{-} \mathrm{D}$ & 16. $\mathrm{S}_{-} \mathrm{D}_{-}$ \\
\hline 6. $\mathrm{P}-\mathrm{CK}$ & 17. $\mathrm{COO}_{-}$ \\
\hline $\mathrm{KI}_{--}$ & 18. $\mathrm{D}_{--} \mathrm{R}$ \\
\hline $\mathrm{A}_{-} \mathrm{T}$ & 19. $\mathrm{FR}_{-} \mathrm{T}$ \\
\hline $\mathrm{ANG}_{-}-$ & 20. $\mathrm{SH}_{-} \mathrm{RE}$ \\
\hline 10. $\mathrm{W}_{-} \mathrm{N}$ & 21. $\mathrm{W}_{-}$TER \\
\hline 11. _ AGE & \\
\hline
\end{tabular}




\section{PANAS Scale for Anger and Negative Affect}

\section{Personality Questionnaire}

Directions: Answer each question by circling the appropriate number.

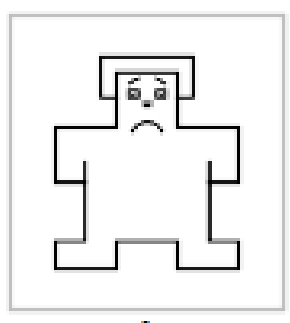

1

Very Slightly

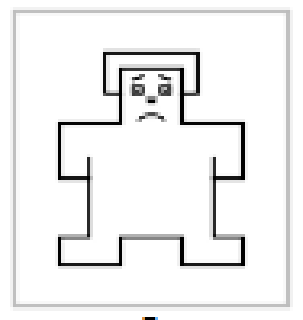

2

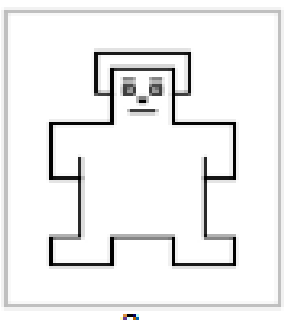

3

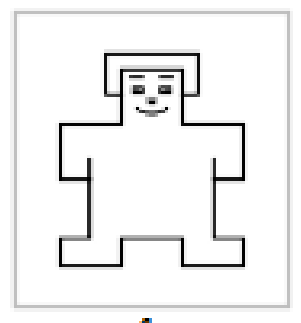

4

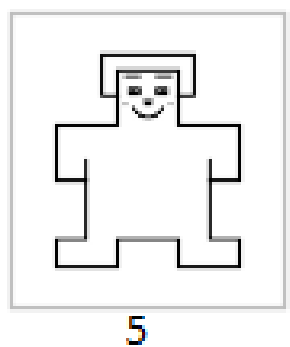

Extremely

How distressed do you feel right now?

How excited do you feel right now?

$$
\begin{array}{lllll}
1 & 2 & 3 & 4 & 5
\end{array}
$$

How alert do you feel right now?

$$
\begin{array}{lllll}
1 & 2 & 3 & 4 & 5
\end{array}
$$

How angry do you feel right now?

$$
\begin{array}{lllll}
1 & 2 & 3 & 4 & 5
\end{array}
$$

How strong do you feel right now?

$\begin{array}{lllll}1 & 2 & 3 & 4 & 5\end{array}$

How enthusiastic do you feel right now?

$\begin{array}{lllll}1 & 2 & 3 & 4 & 5\end{array}$

How irritable do you feel right now?

$$
\begin{array}{lllll}
1 & 2 & 3 & 4 & 5
\end{array}
$$

How proud do you feel right now?

$\begin{array}{lllll}1 & 2 & 3 & 4 & 5\end{array}$

How hostile do you feel right now?

$\begin{array}{lllll}1 & 2 & 3 & 4 & 5\end{array}$

How annoyed do you feel right now?

$$
\begin{array}{lllll}
1 & 2 & 3 & 4 & 5
\end{array}
$$

How nervous do you feel right now?

$\begin{array}{lllll}1 & 2 & 3 & 4 & 5\end{array}$

$$
\begin{array}{lllll}
1 & 2 & 3 & 4 & 5
\end{array}
$$

How upset do you feel right now?

$\begin{array}{lllll}1 & 2 & 3 & 4 & 5\end{array}$

How alert do you feel right now?

$$
\begin{array}{lllll}
1 & 2 & 3 & 4 & 5
\end{array}
$$

How guilty do you feel right now?

$$
\begin{array}{lllll}
1 & 2 & 3 & 4 & 5
\end{array}
$$

How scared do you feel right now?

$$
\begin{array}{lllll}
1 & 2 & 3 & 4 & 5
\end{array}
$$

How excited do you feel right now?

$$
\begin{array}{lllll}
1 & 2 & 3 & 4 & 5
\end{array}
$$

How determined do you feel right now?

$$
\begin{array}{lllll}
1 & 2 & 3 & 4 & 5
\end{array}
$$

How attentive do you feel right now?

$\begin{array}{lllll}1 & 2 & 3 & 4 & 5\end{array}$

How jittery do you feel right now?

$$
\begin{array}{lllll}
1 & 2 & 3 & 4 & 5
\end{array}
$$

How afraid do you feel right now?

$\begin{array}{llllll}5 & 1 & 2 & 3 & 4 & 5\end{array}$




\title{
University of Connecticut
}

\author{
Debriefing Form
}

Principal Investigator: Thomas J. Kehle, PhD

Student Researcher: Koichi Yoshikawa

Study Title: Self-Distancing to Reduce Anger in High School Students

This was a study of self-distancing, the ability think about and see your experiences as if you were an outside observer. After being asked to "recall an interpersonal experience in which you felt overwhelming anger and hostility", you were randomly placed into either a "control" group in which you were told, "Go back to the time and place of the experience you just recalled and see the scene in your imagination. Now see the situation unfold through your own eyes as if it were happening to you all over again. Replay the event as it unfolds in your imagination through your own eyes." or a self-distancing group in which you were told, "Now close your eyes. Go back to the time and place of the experience you just recalled and see the scene in your imagination. Now take a few steps back. Move away from the situation to a point where you can now watch the even unfold from a distance and see yourself in the event. As you do this, focus on what has now become the distant you. Now watch the situation unfold as if it were happening to the distant you all over again. Replay the event as it unfolds in your imagination as you observe your distant self." The script for the control group was intended to have you recall an experience involving anger. The script for the self-distancing group was designed to have you recall an experience involving anger and then see the experience from an outside perspective. "The incomplete word task measured subconscious anger by having some words that could be completed as either neutral words (i.e. M_D as MUD) or aggressive words (i.e. M_D as MAD). The questionnaire asking about emotions had multiple questions about anger and all-around negative emotion. The rest of the questions were just fillers.

You were not told that we were testing self-distancing or what we were measuring so that you would not 1) be distracted with trying to figure out our goal for this research or 2) feel obligated to answer in a non-truthful way. The purpose was not to "trick" you, but to allow you to respond naturally to the experiment and the questionnaires. You may see this as misleading, but we hope that you understand that this was done for an important reason.

We believe this study is important because self-distancing is a simple and quick treatment for reducing anger and other negative emotions such as depression thathas never been tested on adolescents. Sociological studies have found that high levels of student anger and frustration are often linked to aggression and antisocial behaviors ${ }^{1}$.

We are not interested in any one participant's responses. We are only interested in how participants responded in general when combined together. All the information that is collected during the study will be kept confidential. There will be no way of identifying your responses with your identity.

If you feel the procedure for self-distancing may help you in your personal life, please feel free to try using the self-distancing script above. Past research has shown that people who self-distance have higher self-control ${ }^{2}$ and lower stress on their heart ${ }^{3}$. Self-distancing also leads

\footnotetext{
${ }^{1}$ Agnew, 1985; Mazerolle and Piquero, 1997; Mazerolle et al., 2000

${ }^{2}$ Fujita, Trope, Liberman, \& Levin-Sagi, 2006; Trope \&Liberman, 2003, 2010
} 
to lower aggressive thoughts, angry feelings, show less aggressive behaviors, and improve interactions with others ${ }^{4}$.

We ask that you do not discuss this research with other people until all participants have completed the study or afterschool today. If you have any questions or concerns regarding your participation in this study or if you are uncomfortable in any way as a result of answering any of the questionnaire items, then please contact Dr. Thomas J. Kehle, at thomas.kehle@uconn.edu or 860-486-0166 and Koichi Yoshikawa, at koichi.yoshikawa@uconn.edu or 858-371-1162.

\section{References}

Ayduk, O., \& Kross, E. (2008). Enhancing the pace of recovery: Self-distanced analysis of negative experiences reduces blood pressure reactivity. Psychological science, 19, 229231.

Fujita, K., Trope, Y., Liberman, N., \& Levin-Sagi, M. (2006). Construal levels and self-control. Journal of personality and social psychology, 90, 351-367.

Mischkowski, D., Kross, E., \& Bushman, B. J. (2012). Flies on the wall are less aggressive: Self-distancing "in the heat of the moment" reduces aggressive thoughts, angry feelings and aggressive behavior. Journal of experimental social psychology, 48, 1187-1191.

Ray, R. D., Wilhelm, F. H., \& Gross, J. J. (2008). All in the mind's eye? Anger rumination and reappraisal. Journal of personality and social psychology, 94, 133-145.

Trope, Y., \& Liberman, N. (2010). Construal-level theory of psychological distance. Psychological review, 117, 440-463.

Trope, Y., \& Liberman, N. (2003). Temporal construal. Psychological review, 110, 403-421.

${ }^{3}$ Ayduk \& Kross, 2008; Ray, Wilhelm \& Gross, 2008

${ }^{4}$ Mischkowski, Kross, \& Bushman, 2012 


\section{Appendix J \\ Integrity Checklist}

Prior to Experiment

$$
\text { Integrity Checklist }
$$

- Distribute recruitment flyers to homeroom teachers

- Pick up returned flyers

- Initiate parent phone call process

- Send parent permission forms to parents

- Distribute list of potential participants to school officials

- Randomly assign participants to groups

- Deliver reminder memos to homeroom stating where to go when called Introduction (1 minutes)

○ Escort student to experiment room

- Provide assent form

○ Review:

- Ask if parents reviewed info about study

- Explain that details of purpose and procedures will be explained later and why

- Explain basic procedures

- Review exclusion criteria

- Review right to privacy

- Highlight: participants are "volunteers" and can quit at any time

- Inform participants that if they wish to leave for any reason, including a bathroom break or a need to see a counselor, they can raise their hand and write the reason down for the experimenter to read discreetly.

Manipulation

$\circ$ Have read and sign, then collect

- Play manipulation procedures

- "Please close your eyes. Take a minute and recall an interpersonal experience in which you felt overwhelming anger and hostility."

Reflection Task

- Play prompt

○ Control Group will hear, "Go back to the time and place of the experience you just recalled and see the scene in your imagination. Now see the situation unfold through your own eyes as if it were happening to you all over again. Replay the event as it unfolds in your imagination through your own eyes."

- Self-distancing Group will hear, "Now close your eyes. Go back to the time and place of the experience you just recalled and see the scene in your imagination. Now take a few steps back. Move away from the situation to a point where you can now watch the event unfold from a distance and see yourself in the event. As you do this, focus on what has now become the distant you. Now watch the situation unfold as if it were happening to the distant you all over again.

Replay the event as it unfolds in your imagination as you observe your distant self."

- Give 45 seconds

- "Take a moment to stay in this perspective and analyze your emotions." 
Implicit Aggressive Cognition (3minutes)

- Give implicit aggressive cognition form

- Explain directions

- "Here is a list of 21 words incomplete words. Please complete as many as you can to the best of your ability."

- Give 2 minutes

- Collect forms

Panas (1 minute)

$\circ$ Give Panas form

- Explain directions

○ "Lastly, I would like you to fill out this questionnaire of your feelings on a scale of 1 to 5 . As you can see on this form, 1 means very slightly or not at all and 5 means extremely. I will give you a moment to fill this out."

$\circ$ Give enough time to complete

○ Collect form

(For control group only)

- Conclude the trial by playing the self-distancing script "Now close your eyes. Go back to the time and place of the experience you just recalled and see the scene in your imagination. Now take a few steps back. Move away from the situation to a point where you can now watch the even unfold from a distance and see yourself in the event. As you do this, focus on what has now become the distant you. Now watch the situation unfold as if it were happening to the distant you all over again. Replay the even as it unfolds in your imagination as you observe your distant self."

- Give 45 seconds

Debriefing

- Distribute debriefing letter

- Summarize letter

○ Thank for participation

$\circ$ Explain true purpose of the study

- Explain the procedures

$\circ$ Explain why the purpose and procedures were not explained

$\circ$ Describe potential benefits of the findings

- Give a moment to read independently

$\circ$ Ask if there are any question

- Conclusion/ Thank for participation

- Give movie ticket and note that participant is already entered into raffle for an iPad Mini

O

- Remind not to discuss this study's procedures until after everyone has completed the study.

- Note that counselor is available for anyone that may feel upset, angry or agitated 
Table 1

Adolescent Scores on Dependent Variables in Control and Self-Distancing Groups

\begin{tabular}{|c|c|c|c|c|}
\hline & \multicolumn{2}{|c|}{$\begin{array}{c}\text { Control/Self-Immersion } \\
(n=13)\end{array}$} & \multicolumn{2}{|c|}{$\begin{array}{c}\text { Self-Distancing } \\
(n=13)\end{array}$} \\
\hline & $M(S D)$ & $95 \%$ CI & $M(S D)$ & $95 \% \mathrm{CI}$ \\
\hline $\begin{array}{l}\text { Implicit } \\
\text { Aggressive } \\
\text { Cognition }\end{array}$ & $50.62(19.85)$ & {$[62.61,38.62]$} & $56.77(18.31)$ & {$[67.84,45.7]$} \\
\hline Anger & $8.92(4.29)$ & {$[11.51,6.33]$} & $9.46(4.72)$ & {$[12.31,6.61]$} \\
\hline Negative Affect & $19.54(7.88)$ & {$[24.36,14.72]$} & $22.46(9.96)$ & {$[28.48,16.44]$} \\
\hline $\begin{array}{l}\text { Negative Affect } \\
\text { without Anger }\end{array}$ & $11.31(5.49)$ & {$[14.63,7.99]$} & $12.23(5.31)$ & {$[15.44,9.02]$} \\
\hline
\end{tabular}

Note. $\mathrm{CI}=$ confidence interval 
Table 2

Contrast of Control with Self-Distancing Groups

\begin{tabular}{|c|c|c|c|c|c|c|}
\hline & $t(24)$ & $p$ & LL & UL & $\begin{array}{c}\text { Cohen's } \\
d\end{array}$ & $\begin{array}{c}\text { Cronbach's } \\
\text { Alpha }\end{array}$ \\
\hline $\begin{array}{l}\text { Implicit } \\
\text { Aggressive } \\
\text { Cognition }\end{array}$ & -0.82 & 0.42 & -21.61 & 9.3 & -0.32 & -- \\
\hline Anger & -0.3 & 0.76 & -4.19 & 3.11 & -0.12 & 0.91 \\
\hline Negative Affect & 0.83 & 0.42 & -10.23 & 4.38 & -0.32 & 0.91 \\
\hline $\begin{array}{l}\text { Negative Affect } \\
\text { without Anger }\end{array}$ & -0.44 & 0.67 & -5.3 & 3.45 & -0.17 & 0.89 \\
\hline
\end{tabular}




\section{Figure Captions}

Figure 1. Mean score for implicit aggressive cognition

Figure 2. Mean score for anger

Figure 3. Mean score for negative affect

Figure 4. Mean score for negative affect minus anger 


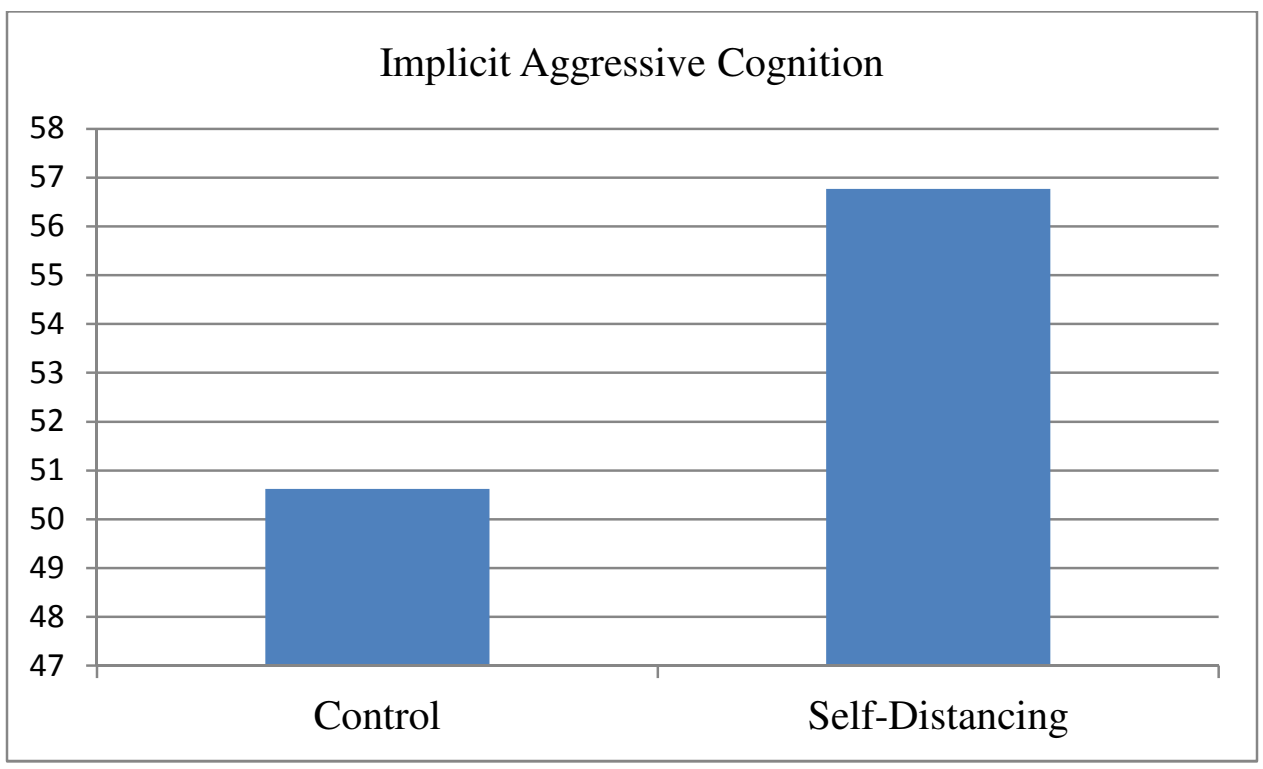




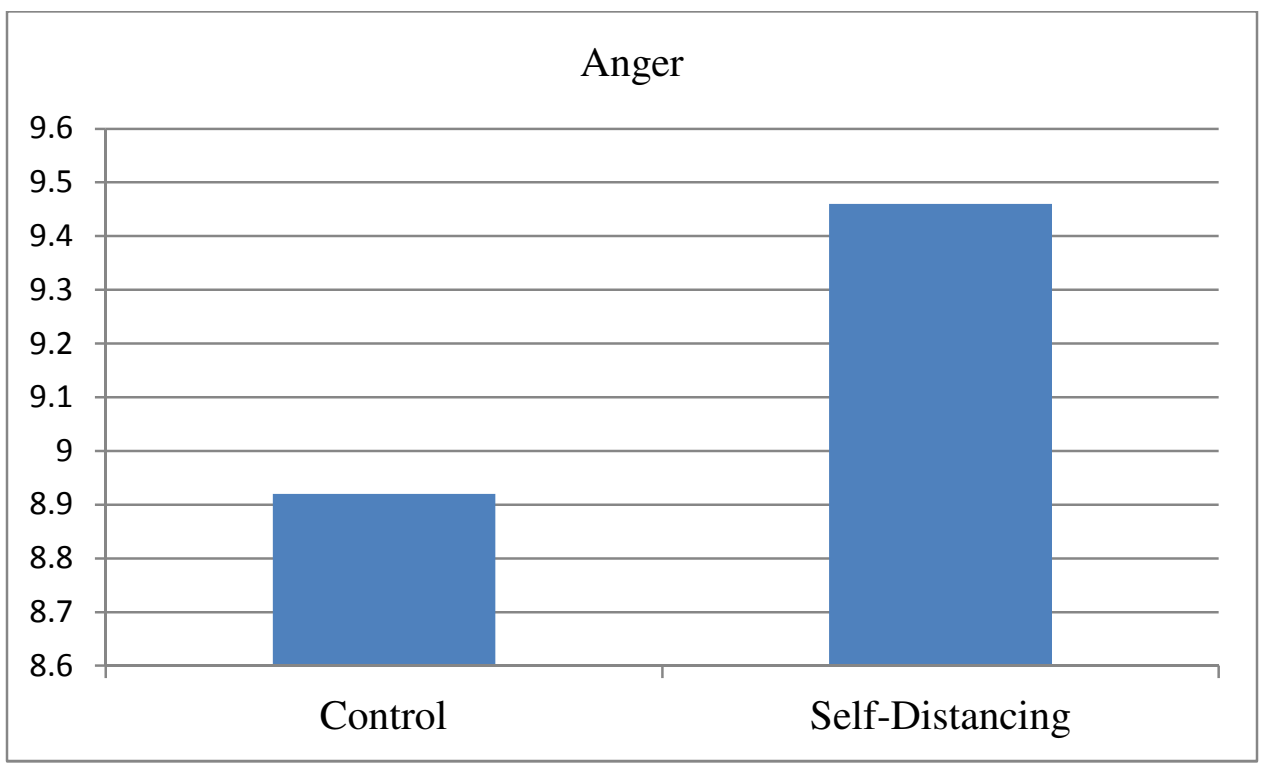




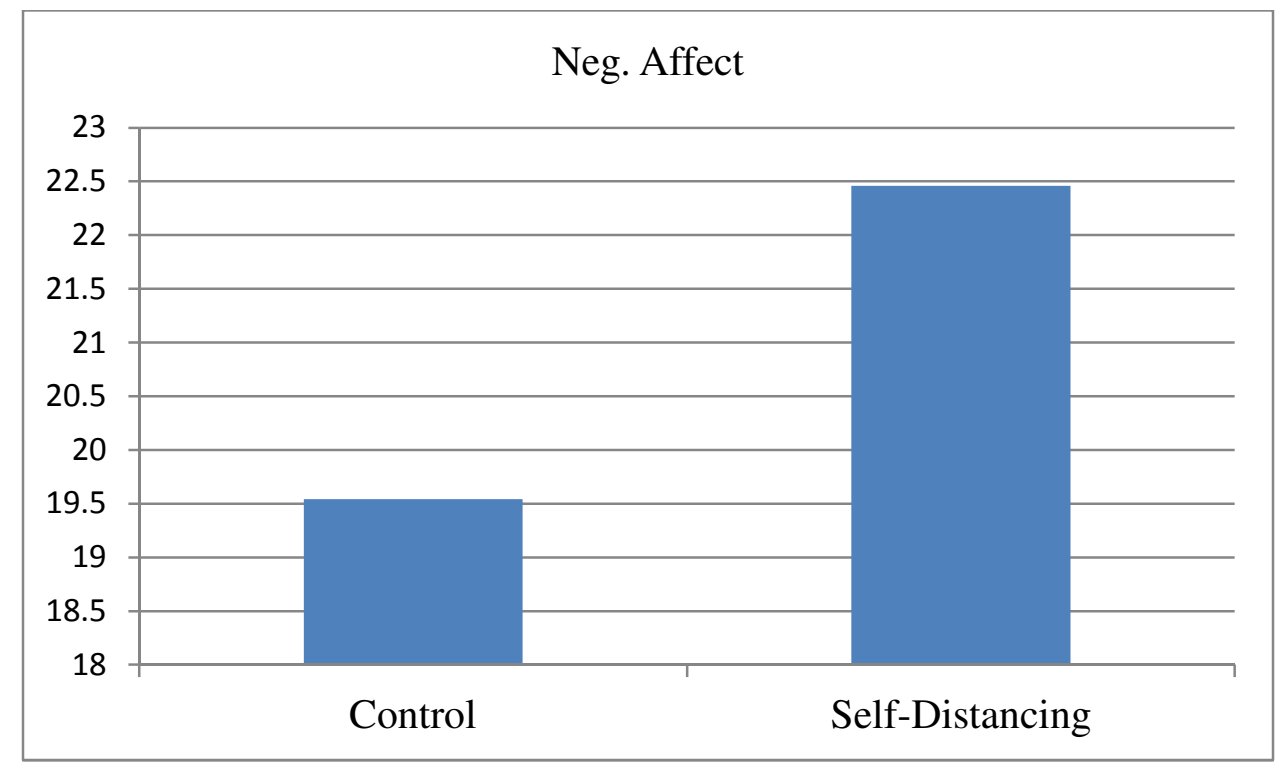




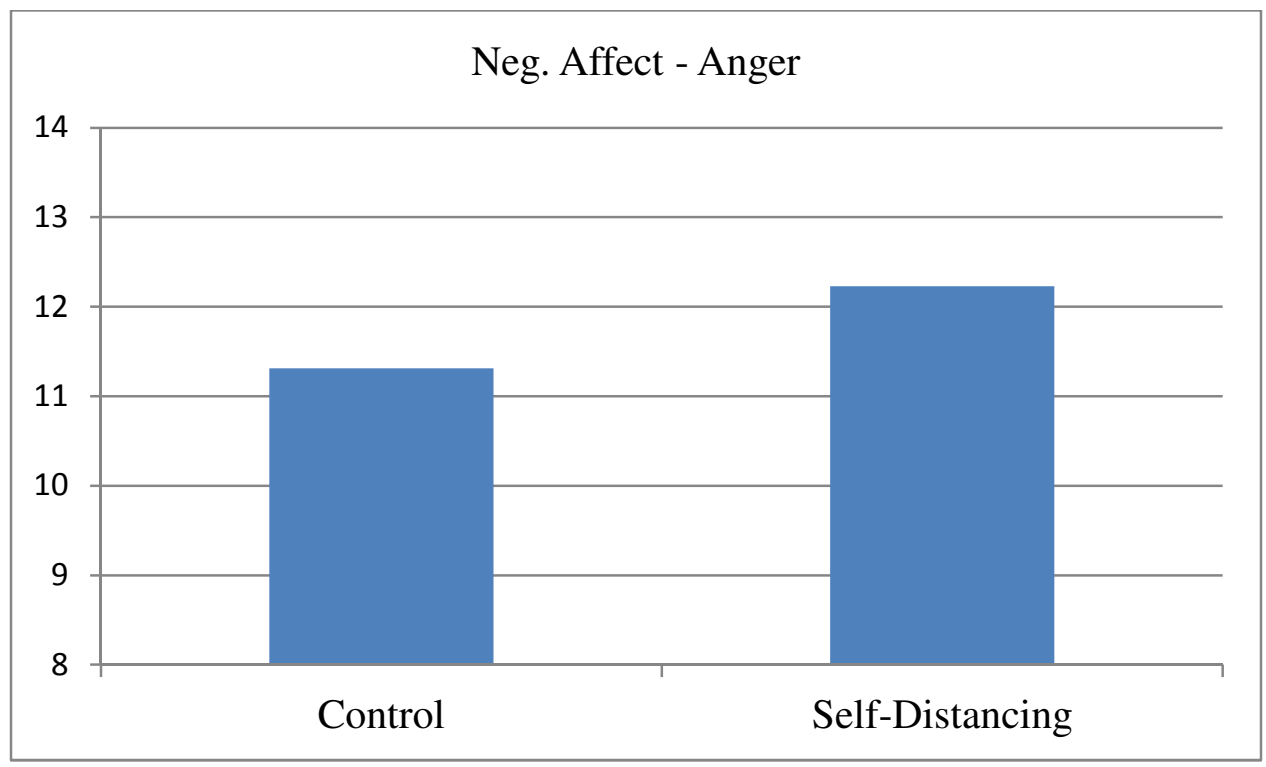

